\title{
Systematic Literature Review to Assess the Cost and Resource Use Associated with Spinal Muscular Atrophy Management
}

\author{
Noman Paracha ${ }^{1} \cdot$ Pollyanna Hudson ${ }^{2} \cdot$ Stephen Mitchell ${ }^{2} \cdot$ C. Simone Sutherland ${ }^{1}$ (i)
}

Accepted: 11 October 2021 / Published online: 11 November 2021

(c) The Author(s) 2021, corrected publication 2022

\begin{abstract}
Background Spinal muscular atrophy (SMA) is a severe neuromuscular disease that is inherited in an autosomal recessive manner with an estimated incidence of 1 in 10,000 live births. The traditional classification of SMA includes five types (Types 0-4 SMA) based on patient age at disease onset and the highest motor milestone achieved. Spinal muscular atrophy leads to progressive muscle denervation, skeletal muscle atrophy and loss of motor function and ambulation, though phenotypes vary along a disease continuum. Regardless of disease severity, or access to treatment, a multidisciplinary approach to care is required to ease the burden of disease. To date, limited global data exist regarding the cost and resource use associated with SMA management.

Objective We planned to perform a systematic literature review to identify studies on cost and healthcare resource use associated with SMA.

Methods A comprehensive search was conducted in 2019 using several electronic databases in addition to supplementary sources and updated in 2021 in order to capture recently published studies. Electronic searches performed in Embase, MEDLINE, Evidence-Based Medicine Reviews and EconLit via the Ovid platform were supplemented by searches of the grey literature (reference lists, conference proceedings, global Health Technology Assessment body websites and other relevant sources). Study eligibility criteria were based on the population, interventions, comparators and outcomes (PICO) framework. Quality assessment of full-text publications was evaluated with reference to a published checklist. To accommodate heterogeneity across studies including countries, currencies, populations, time units and methods of reporting used, costs were reported in Euros in 2019.

Results A total of 51 publications, comprising 49 unique studies of patients with SMA that met all eligibility criteria were included in the final selection. The publications comprised data from 14 countries and seven additional studies that reported multi-national data. Because of the heterogeneity between the different types of SMA, data were frequently reported separately for individuals with Type 1 or early-onset SMA and for Types 2, 3, and 4 SMA or later-onset SMA. Generally, direct medical costs and resource use were reported to be highest for patients with Type 1 SMA, decreasing incrementally for patients with Type 2 and Type 3 disease. Where cost categories were similar, direct costs were much lower in Europe than in the USA. Indirect costs were primarily associated with informal care, which was a substantial burden on patients and families in terms of both cost and time. Cost drivers were generally found to be dependent on SMA type.

Conclusions Long-term robust studies are required to fully elucidate the economic burden of SMA. Considering that motor function can vary broadly, especially in Type 2 SMA, it would be beneficial to understand how costs and resource use are affected by different degrees of ambulation. Reporting data in terms of achieved motor function could also mitigate the challenges of comparing global data studies of small populations. Global, regional, and/or local data collection platforms and disease registry networks could play an important role in helping to address current data gaps.
\end{abstract}

C. Simone Sutherland

simone.sutherland@roche.com

1 F. Hoffmann-La Roche Ltd, Grenzacherstrasse 124 Building 001/OG13, CH 4070 Basel, Switzerland

2 Mtech Access Limited, Bicester, Oxfordshire, UK 


\section{Key Points for Decision Makers}

Spinal muscular atrophy causes a significant burden to patients, caregivers and healthcare systems, although the extent of the burden is dependent on the type of spinal muscular atrophy reported.

Current research demonstrates that disease-modifying therapies can potentially reduce spinal muscular atrophy costs, but more information is needed across all spinal muscular atrophy types.

It is recommended that future cost and resource evaluations in spinal muscular atrophy should be reported according to the degree of ambulation by patients.

\section{Introduction}

Spinal muscular atrophy (SMA) is a severe neuromuscular disease that is inherited in an autosomal recessive manner with an estimated incidence of 1 in 10,000 live births [1]. Approximately $95 \%$ of SMA cases are caused by homozygous deletions in the survival of the motor neuron 1 (SMN1) gene that encodes the SMN protein; the remaining cases arise from heterozygous deletions and point mutations in SMN1 [2]. While another SMN gene, SMN2, also encodes the SMN protein, the majority of protein produced by this gene is unstable and therefore insufficient to counteract deficiency in $S M N 1$ [3, 4]. Individuals carry a variable number of copies of the SMN2 gene, and in SMA, the number of copies is typically inversely correlated with the severity of disease [5, 6]. Despite ubiquitous expression, motor neurons are particularly sensitive to insufficient SMN levels, leading to progressive muscle denervation, skeletal muscular atrophy, overall weakness and loss of motor function and ambulation [7-10]. Muscle atrophy can lead to diseaseassociated complications such as pneumonia, scoliosis, contractures and difficulty with sleep and nutrition, all of which can impact survival and reduce quality of life, and can result in the need for respiratory, orthopaedic, mobility and nutritional support [11-14].

The traditional classification of SMA includes five types (Types 0-4 SMA) based on patient age at disease onset and the highest motor milestone achieved [7, 9, 15-17]. SMA phenotypes vary along the disease continuum; at the extremes, Type 0 SMA causes foetal or neonatal death, whereas Type 4 SMA is the mildest form of SMA which manifests during adulthood [7,9]. In the absence of disease-modifying therapies (DMTs), infants with Type 1 SMA (also known as Werdnig-Hoffmann disease) are unable to sit and life expectancy may not extend 2 years [7, 16, 17].
In Type 2 SMA, muscle weakness may develop between 7 and 18 months of age; these individuals achieve the ability to sit, and some can stand with support, but they are never able to walk [7, 9]. Diagnosis of Type 3 SMA (also known as Kugelberg-Welander disease) occurs after 18 months of age in individuals who achieve the ability to walk but are likely to progressively lose function, whereas individuals with Type 4 SMA are ambulatory at initial diagnosis, which occurs in adulthood [7, 9]. Of Types 1-3 SMA, the incidence of Type 1 SMA is estimated at $\sim 60 \%$, whereas Type 2 and Type 3 SMA each have an estimated incidence of $~ 20 \%$ [1]. It is estimated that $35 \%$ of the global SMA population are adults [18]. In the USA, the prevalence of Types 1, 2, and 3 SMA cases was projected to be 8526,9429 and 10,333 in 2016, respectively [19].

Three DMTs that increase SMN levels via distinct administration approaches have been approved in the USA and Europe: nusinersen (Spinraza ${ }^{\circledR}$; Biogen Inc., Cambridge, MA, USA) [20, 21], onasemnogene abeparvovec-xioi (Zolgensma ${ }^{\circledR}$; AveXis Inc., Bannockburn, IL, USA) [22, 23] and risdiplam (Evrysdi ${ }^{\circledR}$; Genentech Inc., South San Francisco, CA, USA) [24, 25]. Nusinersen is an intrathecally administered antisense oligonucleotide that modifies $S M N 2$ pre-messenger RNA splicing to increase SMN protein production [26], while onasemnogene abeparvovec is an intravenous gene therapy that introduces a copy of the SMN1 gene [27]. Risdiplam is an oral small molecule that increases SMN protein levels by modifying SMN2 messenger RNA splicing [28]. Nusinersen, onasemnogene abeparvovec and risdiplam are changing the management of SMA from previously supportive approaches to treatments that can alter the natural history of the disease [29]. Subsequent to the approval of nusinersen by the European Medicines Agency, a survey across 26 European countries revealed that although almost 95\% (94.7\%) of patients with SMA wanted to initiate an approved treatment, nearly three quarters $(73.2 \%)$ of participants with SMA in a recent European survey were not receiving treatment, with a lack of access cited as the most common reason [30].

A lack of prognostic factors and biomarkers to detect positive responses to DMTs means it can be difficult to establish treatment efficacy despite long-term drug use [31]. Several validated measures of motor function in SMA exist and are used to monitor disease progression, such as the Children's Hospital of Philadelphia Infant Test of Neuromuscular Disorders (CHOP-INTEND) [32], the Hammersmith Infant Neurological Examination Part 2 (HINE-2) scores [33], the Hammersmith Functional Motor Scale-Expanded (HFMSE) [34], the Revised Upper Limb Module (RULM) [35], the 6-Minute Walk Test (6MWT) [36], the Bayley Scales of Infant Development (BSID) [37] and the 32-item Motor Function Measure (MFM32) [38]. 
Regardless of the severity of SMA an individual has, or access to treatment, a multidisciplinary approach to care is required to ease the burden of disease $[11,12,14]$. The first published recommendations for an international SMA standard of care [14] were updated in 2018 to reflect improvements in SMA management approaches such as non-invasive ventilation and enteral feedings $[11,12]$. However, as SMA is a rare disease, patient outcome studies tend to involve relatively small patient populations, precluding a comprehensive understanding of the burden of SMA to patients, their families and caregivers. Additional hindrances to understanding rare diseases such as SMA include small and geographically diverse patient populations [18], delays in diagnosis [39], disparities in health insurance coverage [40,41] and varied access to specialised treatment options [41]. Family and caregiver support also play a crucial part of SMA management, including help with respiratory function, daily movement and activities, feeding or digestive issues, and responding to medical emergencies. Current recommendations for SMA management include the at-home use of assistive devices, for example, respiratory support equipment and wheelchairs, and adaptive home and transportation modifications [11, 12].

To date, limited global data exist regarding the cost and resource use associated with SMA management. The objective of this systematic literature review (SLR) was to identify studies on costs and healthcare resource use associated with SMA. We then examine in more detail costs (direct and non-direct medical costs, indirect costs and cost drivers) and healthcare resource use associated with the management of SMA.

\section{Methods}

\subsection{Search Strategy and Selection Criteria}

An SLR was performed to identify available evidence of healthcare costs and resource use associated with SMA. The Preferred Reporting Items for Systematic reviews and MetaAnalyses for Protocols 2020 [42] guidelines were followed to identify and screen scientific literature and extract data [42]. A comprehensive search was performed using several electronic databases (Embase, MEDLINE, Evidence-Based Medicine Reviews and EconLit) on 29 August, 2019. Additional searches (hand searching) of congress proceedings, reference lists of included publications, Health Technology Assessment bodies, and searches of additional sources and websites were also conducted to identify relevant evidence (Table 1 of the Electronic Supplementary Material [ESM]). Eligibility criteria included cost and resource use studies conducted in any patient with SMA. The search was updated on 29 July, 2021 to ensure that any recently published studies were captured. The full search strategies (up to 29 July,
2021), including free-text words, subject index headings (e.g. MeSH), the relationship between search terms (e.g. Boolean) and database start dates are provided in Table 2 of the ESM. The literature searches in the database covered several decades; therefore, few studies included in the SLR examined the impact of treatment with DMTs on costs and resource use. Eligibility criteria were based on the population, interventions, comparators, and outcomes (PICO) framework [43] to identify relevant data (Table 3 of the ESM). Because of the expected paucity of relevant data for patients with SMA, the scope of searches was initially broad to include patients with other neuromuscular and neurodegenerative disorders including, but not limited to, myodystrophy, muscular dystrophy and amyotrophic lateral sclerosis; however, publications relevant to these disorders were not analysed further. Studies that included patients with any type of SMA (Types 1, 2, 3 and/or 4) were selected for further analysis. No limitations were imposed on the search strategy regarding intervention, geography, the language of publication or the publication date (Table 3 of the ESM).

\subsection{Data Extraction}

Data extraction was carried out by the first reviewer and checked for accuracy and completeness by a second reviewer and any inconsistencies were resolved through discussion.

\subsection{Assessment of Bias and Quality of Evidence}

Quality assessment of eligible cost/resource use studies was performed using the checklist adapted to cost of illness by Molinier et al. [44].

\subsection{Cost Adjustments}

To accommodate heterogeneity across studies including countries, currencies, populations, time units and methods of reporting used, costs were adjusted to account for inflation and were reported in Euros (EUR). Non-US costs were converted to EUR 2019 values using the Harmonised Index of Consumer Prices extracted from Eurostat [45]. US costs were converted to 2019 prices using the Consumer Price Index for all Urban Consumers extracted from the US Bureau of Labor Statistics [46]. Costs reported in currencies other than EUR were converted to EUR using purchasing power parities [47] for gross domestic product. For studies in which the reference year of costs was unclear, the year of publication was assumed for the base year (with the exception of 2021 publications for which the base year was assumed to be 2020). 


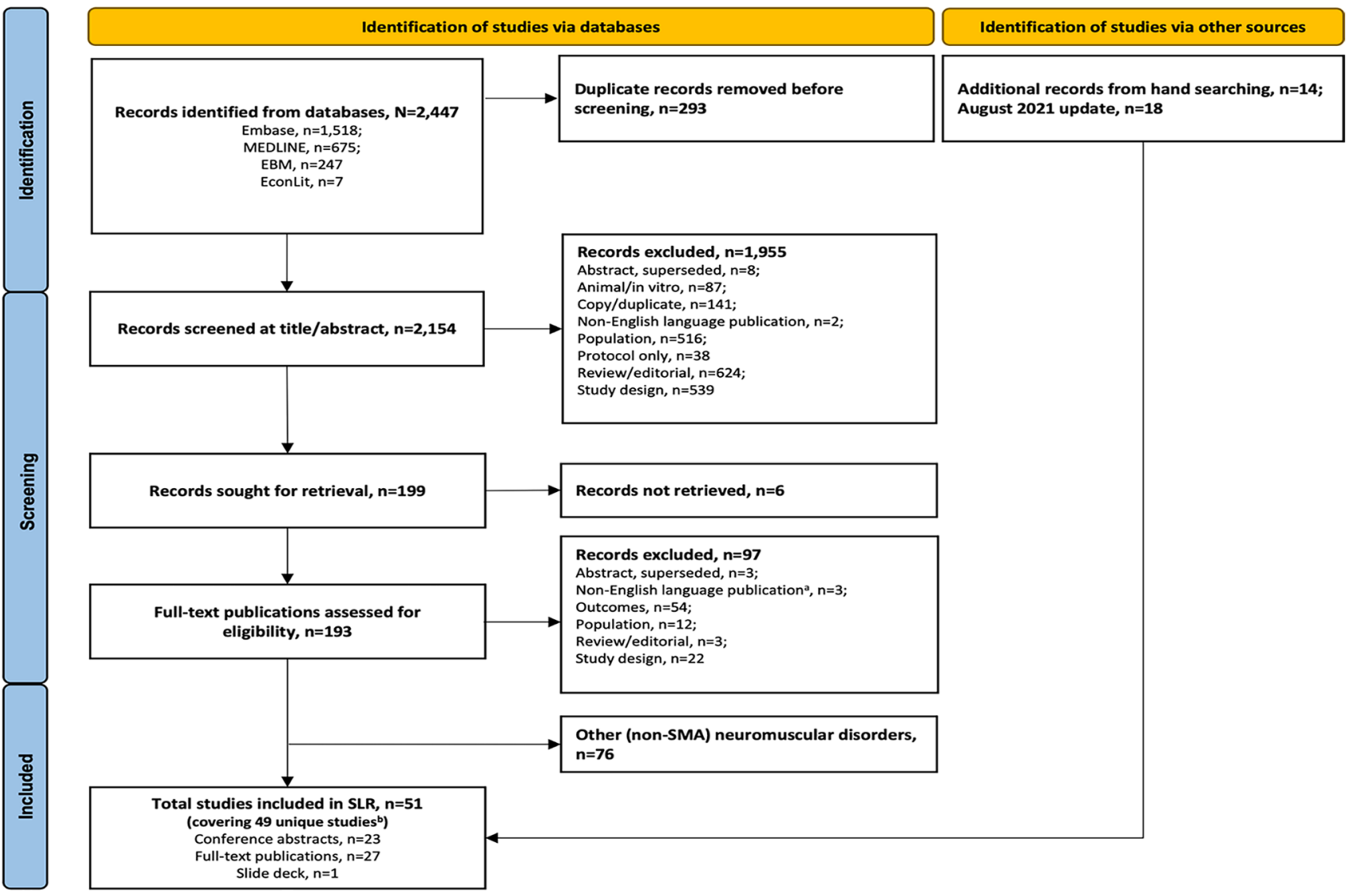

Fig. 1 Study flowchart. Fifty-one publications reporting costs and resource use in spinal muscular atrophy (SMA) were included in this

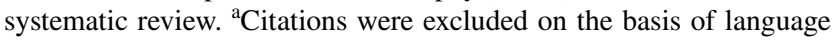
if: a they did not have an English abstract or $\mathbf{b}$ they had an English abstract but relevant data were not reported in the abstract. ${ }^{\mathrm{b}}$ Covering

\section{Results}

\subsection{Description of Identified Studies}

The original electronic database searches conducted in August 2019 identified 2447 records. Following removal of 293 duplicates, 2154 titles and abstracts were screened, and 199 full-text records were deemed potentially relevant before 103 were excluded based on PICO criteria. Fourteen additional records were identified via hand searching. A total of 34 publications, comprising 32 unique studies of patients with SMA that met all eligibility criteria were identified in the original search. Two conference abstracts were linked $[48,49]$, and one conference abstract and one manuscript were linked [50, 51]. However, these abstracts and manuscripts contained unique data; therefore, all were included as discrete publications. The update search in July 2021 yielded an additional 17 publications including 11 full-text publications and six conference abstracts; one abstract had an associated poster [52] (Fig. 1).
49 unique studies; two full publications and two conference abstracts were linked studies; both have been retained in the current report as they each report unique relevant data. $E B M$ evidence-based medicine reviews, $S L R$ systematic literature review

The final list of 51 publications comprised 27 full-text publications [50, 53-78], 23 conference abstracts [48, 49, 51, 52, 79-97] and one slide deck [98]. Cost and resource use data were reported in 23 publications [48, 50, 53-57, $60,61,68,70-77,79,84,85,92,98]$. Cost data only were reported in nine publications [58, 59, 83, 86, 93-97], whereas resource use data only were found in 19 publications [49, 51, 52, 62-67, 69, 78, 80-82, 87-91].

The publications comprised data from 14 countries, including the USA $(n=20)[48-50,53,54,56,57,60,63$, $70,74,77,80,84-86,88,91-93]$, UK $(n=5)$ [52, 68, 81, 89, 98], Italy $(n=2)$ [59, 83], Australia $(n=2)$ [64, 71], Canada $(n=1)$ [75], Germany $(n=1)$ [55], Croatia $(n=1)$ [87], Korea $(n=1)$ [65], Japan $(n=1)$ [66], France $(n=1)$ [79], Spain $(n=4)$ [58, 72, 73, 78], Sweden $(n=1)$ [61], Russia $(n=2)[94,97]$ and Turkey $(n=1)$ [96]. Seven studies reported multi-national data [62, 67, 69, 76, 82, 90, 95].

The following study designs were adopted across the 49 unique studies: retrospective analyses $(n=35)$ [48, 50, 53-60, 63, 65, 66, 68, 70, 72-74, 77-93], cross-sectional 
analysis $(n=7)[52,69,71,75,76,95,96]$, cost analysis $(n$ $=2)$ [94, 97], exploratory qualitative analysis $(n=1)$ [64], prospective cohort study $(n=1)$ [62], economic evaluation (reporting original cost data; $n=1)$ [61], survey $(n=1)$ [98] and a symposium briefing report $(n=1)$ [67]. Because of the heterogeneity between the different types of SMA, data were frequently reported separately for individuals with Type 1 $(n=11)$ [48, 54, 57, 63, 65, 66, 68, 81, 84, 91, 93]; Types 1-3 SMA ( $n=11$; each type reported separately [52, 55, 58, 59, 67, 69, 71, 75, 76, 96, 98]; Type 3 SMA including subgroups $(n=1)$ [82]; and adult patients with SMA $(n=1)$ [74] or were reported for a mixed population of individuals with SMA: infantile-onset and other SMA (excluding Type 4 SMA; $n=1$ ) [79]; infantile-onset ( $\leq 7$ years) and later-onset (2-12 years) SMA $(n=1)$ [61]; Type 1 SMA and other SMA (including Type 4 SMA; $n=2$ ) [50, 97]; early-onset SMA (patients with Types 1, 2 and 3 SMA aged $\leq 3$ years); and other SMA (later-onset Types 2 and 3 SMA in addition to Type 4 SMA) $[n=1]$ [60]—reported separately for infantile-onset, childhood-onset and juvenile-onset SMA $(n=1)$ [70]; reported separately for patients with infantile-onset, childhood-onset and late-onset SMA $(n=1)$ [77]; a mixed population with Types 1, 2 and 3 SMA $(n=1)$ [95]; a mixed population with Types 2 and 3 SMA $(n=1)$ [64]; a mixed population with Types 2 and 3 SMA including subgroups $(n=1)$ [62]; a mixed population with Types 2 and 3 and unreported SMA type $(n=1)$ [88]; a mixed population with Types 1, 2, 3 and 4 SMA $(n=1)$ [73]; and a mixed population with SMA in which SMA type was neither specified nor reported $(n=11)$ [53, 56, 80, 83, 85-87, 89, 90, 92, 94, 99].

Of the 51 publications included in the SLR, 12 included data that examined the use of DMTs nusinersen and onasemnogene abeparvovec; four were full-text publications [50, 61, 63, 68], whereas eight were abstracts [48, 49, $51,81,88,90,91,93]$. Because of earlier approval in the USA and Europe for nusinersen, most of the 12 publications examined nusinersen only [50, 51, 61, 68, 81, 88, 90, 93], whereas three publications compared treatment with onasemnogene abeparvovec vs nusinersen [48, 49, 63], and one publication examined onasemnogene abeparvovec [91]. No data are currently available for the effect of treatment with risdiplam on cost and resource use as a result of the recent approval of risdiplam in the USA and Europe.

Overall, 30 studies reported direct cost data $[48,50$, 53-61, 68, 70-74, 76, 77, 79, 84-86, 92-98], 22 studies reported disaggregated direct costs $[48,50,52,53,55$, $58-61,68,71,73-77,79,84-86,92,98]$ and 26 studies reported aggregated direct costs $[50,53-60,70-74,76,77$, $81,84,85,92-98]$. Of the 30 studies reporting direct cost data, 20 studies used a bottom-up approach [53-61, 70, 71, $73,74,76,77,81,84,95-97]$ and four studies used a topdown approach $[50,79,85,92]$. Six studies did not specify the method of cost collection [48, 72, 86, 93, 94, 98]. Forty publications reported data on resource use (Table 4 of the ESM), which included requirement for respiratory support $(n=30)$, length of stay in hospital $(n=19)$, number of hospital admissions $(n=24)$, requirement for nutritional support $(n=18)$, outpatient or specialist visits $(n=20)$, medication (non-DMT) resource use $(n=15)$, patients requiring carers $(n=16)$, physiotherapy $(n=9)$ and use of assistive devices or medical aids, such as care aids or adaptive beds $(n=14)$.

\subsection{Direct Medical Costs and Resource Use}

Direct medical costs associated with inpatient and outpatient hospitalisation, consultations with specialists and other healthcare providers, current treatment and posology (excluding DMT costs), tests/examinations and rehabilitation were of primary interest for this SLR. Thirty studies reported direct medical cost data (data from 20 studies are shown in Table 1) and 35 studies recorded resource use data aligned with the categories described for direct medical costs.

Generally, direct medical costs and resource use were reported to be highest for patients with Type 1 SMA, decreasing incrementally for patients with Types 2 and 3 SMA [55, 59, 60, 71, 83]. A resource use study in Germany [55] found the consumption of medical resources to be highest in patients with Type 1 SMA, particularly for outpatient medical consultations, inpatient treatment and artificial nutrition; $67 \%$ of patients with Type 1 SMA required inpatient treatment compared with only $17 \%$ of patients with Type 2 SMA, and 7\% with Type 3 SMA [55]. The same study found that $100 \%$ of patients with Type 1 SMA required outpatient medical consultation compared with 79\% of patients with Type 2 SMA, and 54\% with Type 3 SMA [55]. Consumption of rehabilitation resources was $100 \%$ for Type 1, 96\% for Type 2, and 79\% for Type 3 SMA; however, use of sleep laboratory diagnostics, drug treatments, medical aids and respiratory management was most frequent in patients with Type 2 SMA, and the highest need for psychological assistance occurred in patients with Type 3 SMA [55]. Direct costs incurred by the Italian National Health Service were $€ 3385.49, € 1828.23$ and $€ 767.20$ per patient per annum with Types 1, 2 and 3 SMA, respectively [59]. An analysis of hospital admission records from 1997 to 2015 in Spain revealed that the average annual cost per hospital admission was associated with length of stay and SMA type [72]. Another study of records collected from 2006 to 2016 in the USA of 14 geographically dispersed health plans found that compared with age-matched controls, the average total healthcare costs were 54.2, 33.7 and 3.1 times higher in infantile-onset, childhood-onset and lateronset SMA cohorts, respectively [77]. Mean intensive care unit and non-intensive care unit (inpatient only) costs over 


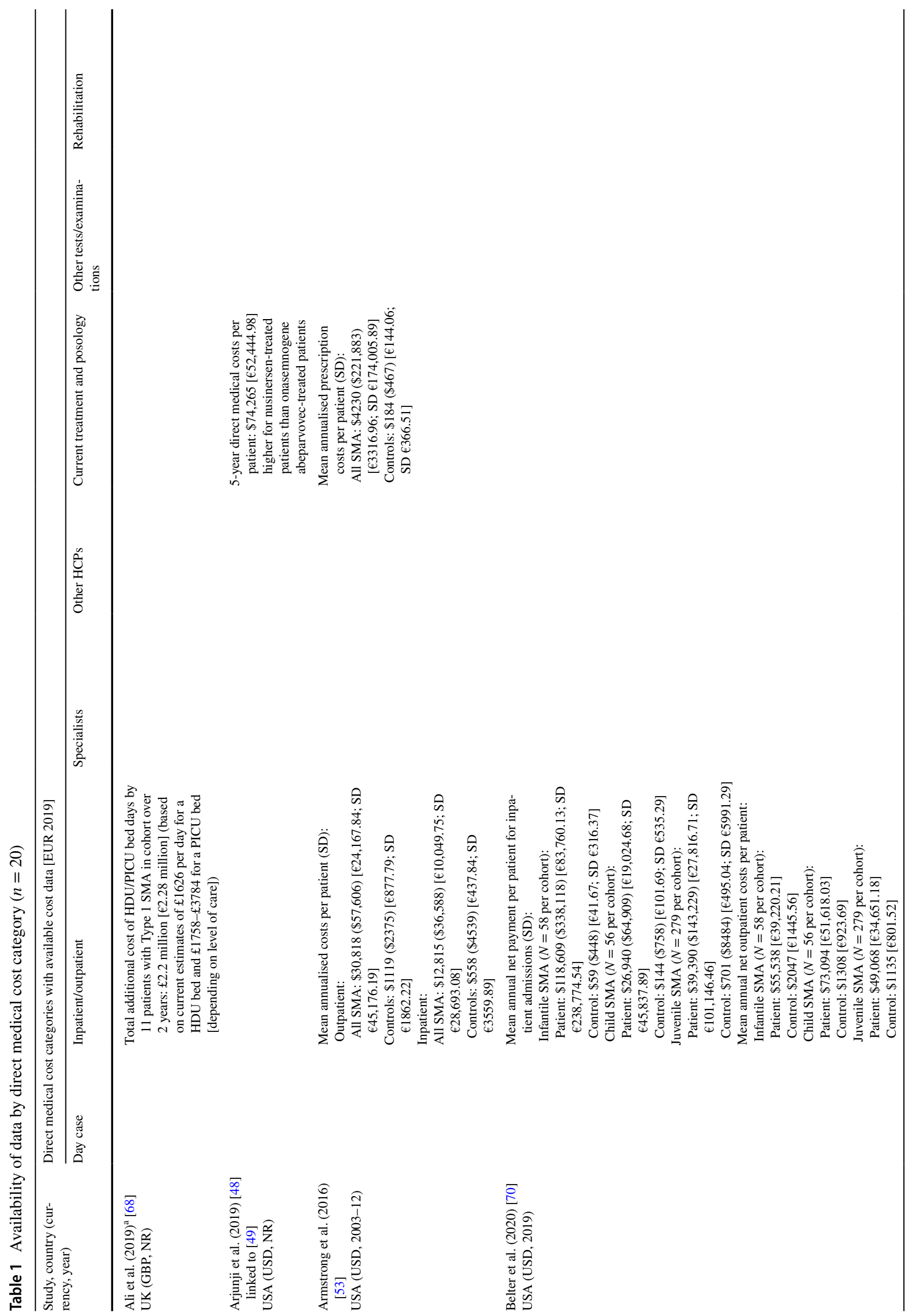




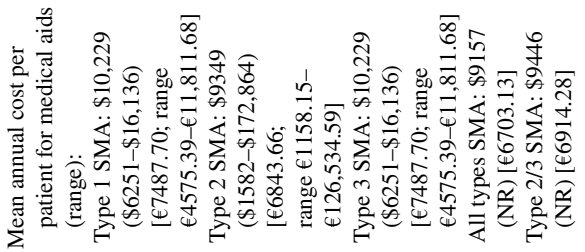

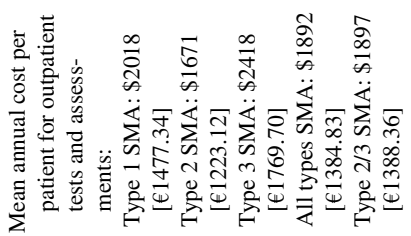

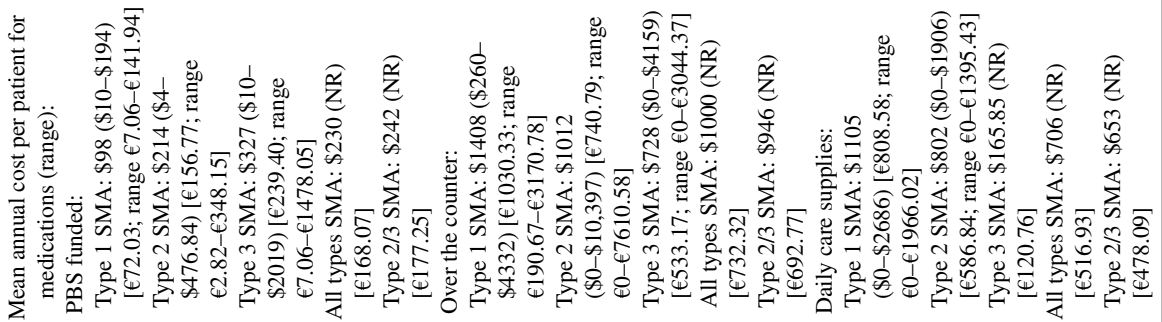

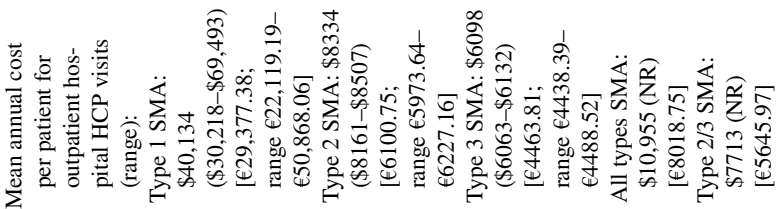




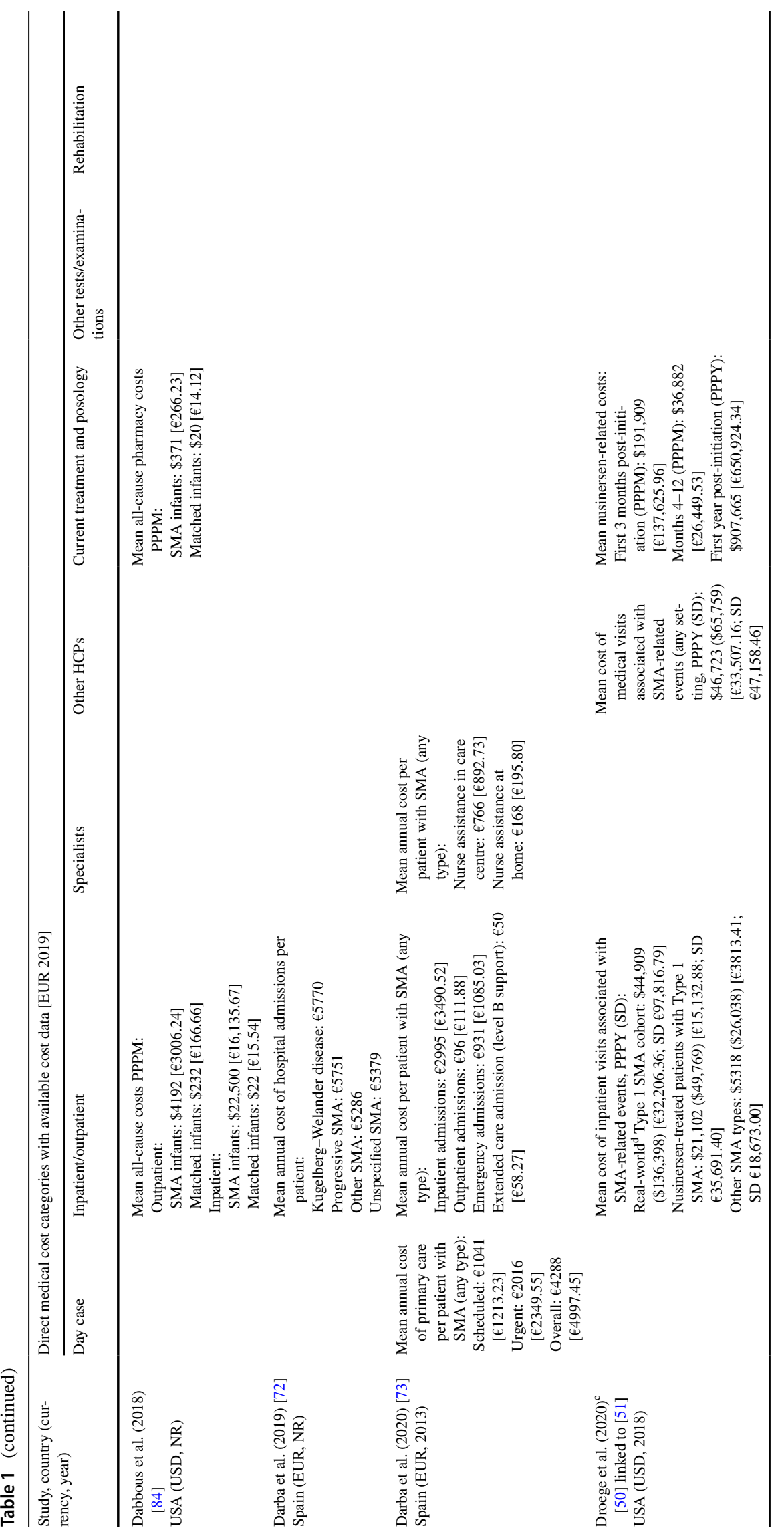




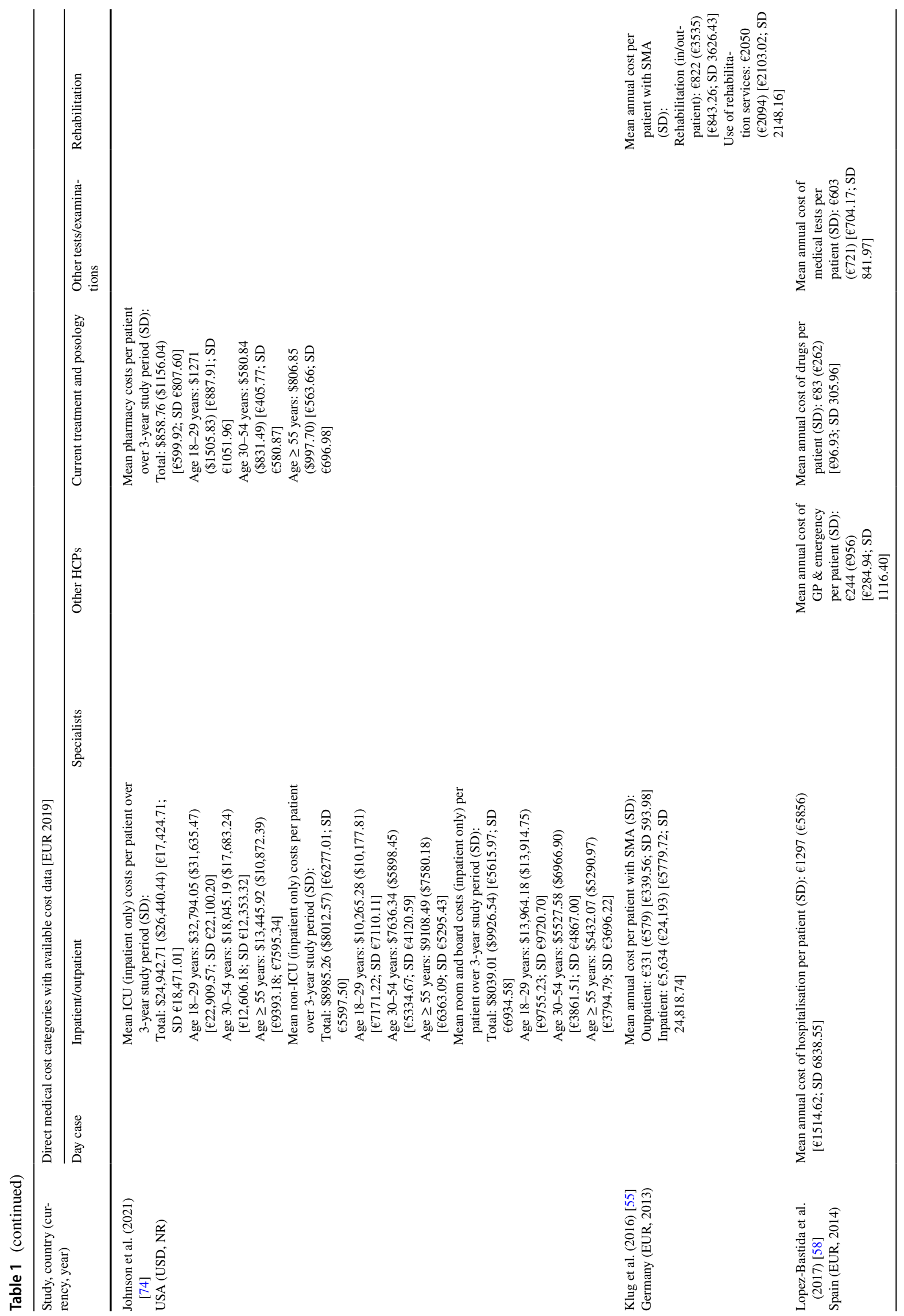



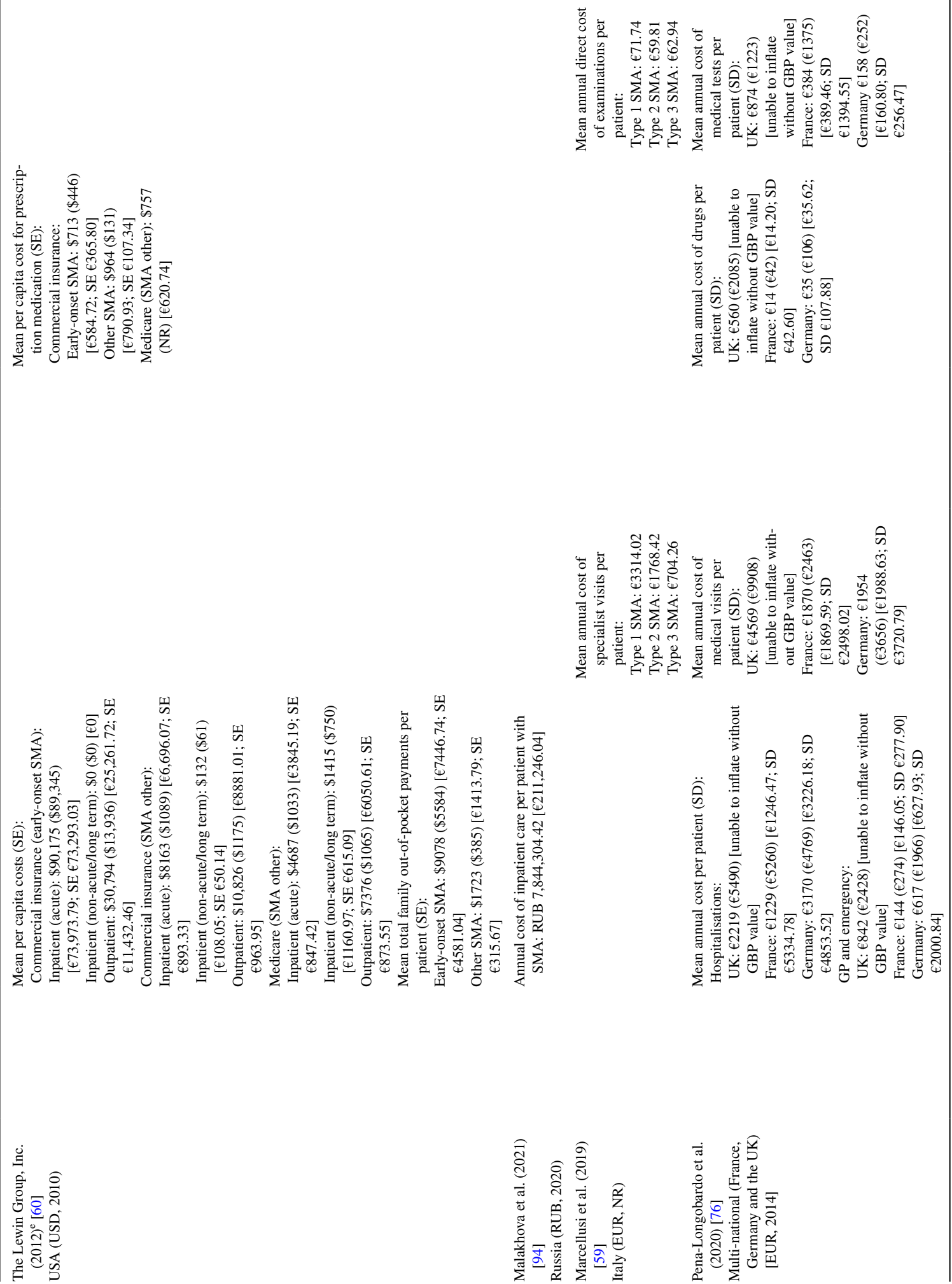


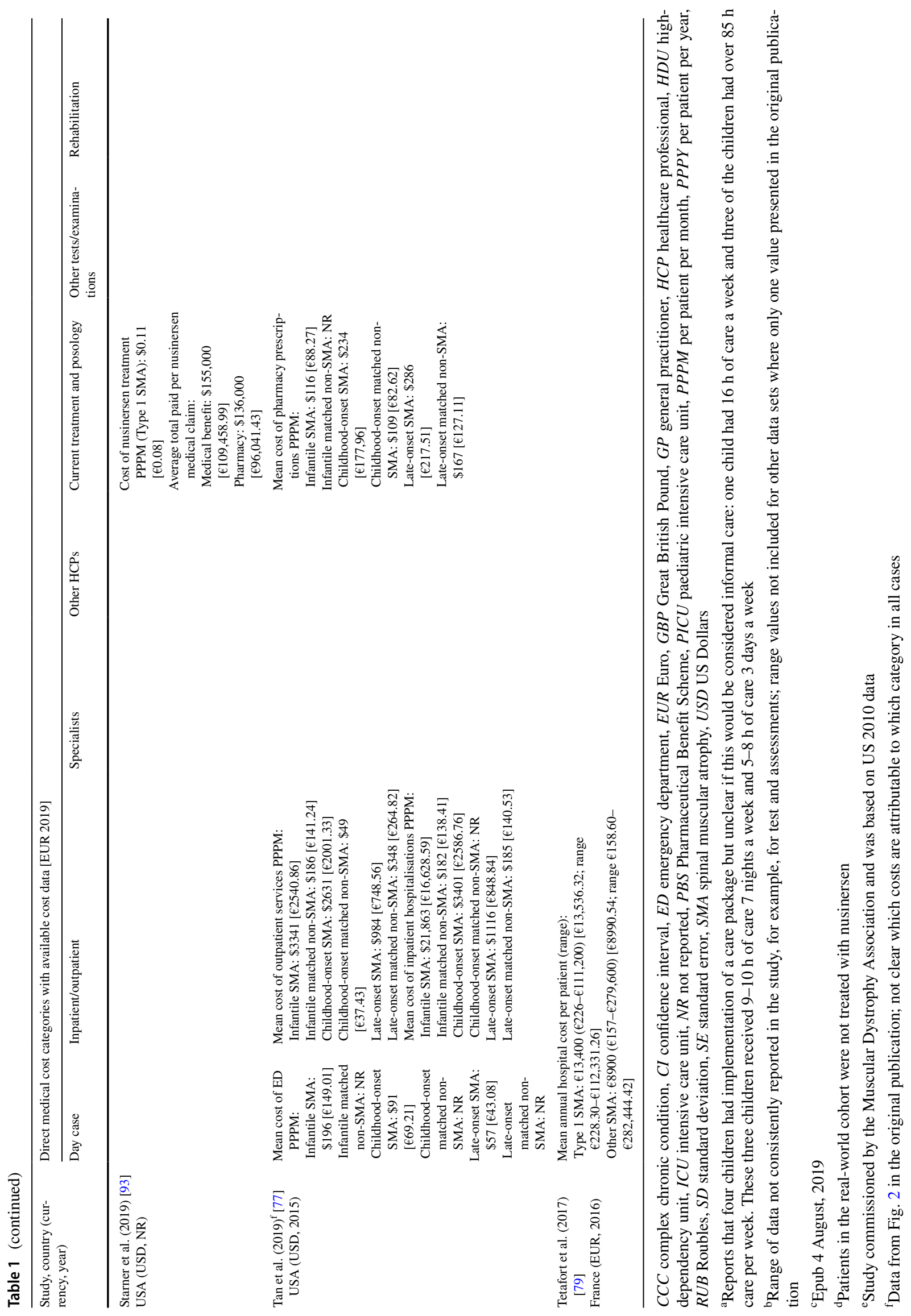


a 3-year study period were higher for patients with SMA in the 18-29 years age group, compared with older patients with SMA [74]. Of households of children with Type 1, 2 or 3 SMA in Australia between 2016 and 2017, 56\% of total costs were attributed to direct costs, and the average total indirect healthcare costs were highest for households with a child with Type 2 SMA [71].

However, given the variation in life expectancy by SMA type, in 2018, D'Angiolella et al. [83] noted that patients with Types 2 and 3 SMA will incur higher costs over a lifetime compared with patients with Type 1 SMA. The mean annual cost per patient with SMA in Spain was estimated to be $€ 33,721$ (EUR 2014), with direct healthcare costs, such as medical visits and hospitalisation, accounting for $32.3 \%$ ( $€ 10,882$; EUR 2014) of the total cost and direct nonhealthcare costs for the remaining $67.7 \%$ (€22,839; EUR 2014) [58].

Where cost categories were similar, direct costs were much lower in Europe than in the USA. In Italy, annual direct costs incurred by a patient were reported to be $€ 1244.81$, €3414.82 and $€ 2234.29$ per patient with Types 1, 2 and 3 SMA, respectively [59]. In Germany, the mean annual outpatient and inpatient cost per patient with SMA was $€ 339.56$ and $€ 24,193$, respectively [55]. In Spain, the mean annual cost per patient with any type of SMA for outpatient and inpatient admissions was $€ 111.88$ and $€ 3490.52$, respectively [73]. The mean per capita outpatient cost in the USA was $€ 25,261.72$ and $€ 8881.01$ for early-onset SMA and other SMA, respectively [60]. In the USA, inpatient costs per patient per month were $€ 22,500$ for infants with SMA compared with $€ 15.54$ for age-matched infants without SMA.

\subsection{Effect of Treatment with DMTs on Cost and Resource Use in SMA}

Preliminary data on the effect of treatment with DMTs on cost and resource use were identified in this SLR. No DMTrelated costs and resource use were found in Types 2 and 3 SMA. One published full-text article revealed that patients with Type 1 SMA who initiated treatment with nusinersen had a lower average number of inpatient days per person per year compared with patients with Type 1 SMA who were not treated with nusinersen (4.6 days vs 14.1 days, respectively [50]). Short-term follow-up of patients treated with nusinersen showed that invasive respiratory support may still be required despite treatment with a DMT [81]. Another study found that although cost and resource use in nusinersentreated patients were substantial, a reduction in associated costs occurred 3 months after initiation of treatment [51]. Two abstracts, published by the same research group, suggested that onasemnogene abeparvovec, a single-dose treatment, may lead to lower estimated direct medical costs for patients with Type 1 SMA compared with treatment with nusinersen [48, 49].

\subsection{Direct Non-Medical Costs and Resource Use}

Direct non-medical costs and resource use include those associated with travel (e.g. distance to treatment centre by car and/or public transport), home adaptation and assistive devices (i.e. respiratory support, wheelchairs and communication devices). Twelve studies reported direct non-medical costs and/or resource use data (results from 11 studies are shown in Table 2; one study [97] reports an overall cost and direct non-medical costs are not reported separately). Of these studies, seven highlighted a significant travel burden on patients and caregivers. Goble et al. [86] reported that $65.9 \%$ of patients living in urban areas, and $99.5 \%$ of patients living in rural areas of the USA experienced a significant travel burden to visit their nearest SMA care centre. Patients also reported having to pay out-of-pocket expenses for flights and hotel accommodation to attend treatment centres [86]. A survey of 188 patients with Type 1, 2 or 3 SMA found that the mean annual out-of-pocket costs incurred for health materials, travel and accommodation (associated appointment costs and hospital stays) was $€ 8329.68$ per patient [98]. A study conducted in Australia reported that Type 2 SMA was associated with the highest mean annual cost per patient for travel (€2386.91) compared with Type 1 SMA (€523.28) or Type 3 SMA (€355.92) [71].

Home and/or vehicle modifications were reported in six studies $[52,55,59,60,71,75]$. A study conducted in the USA reported that the mean annual cost per patient associated with moving or modifying their home was $€ 3023.19$ and $€ 2780.26$ for patients with early-onset SMA and lateronset SMA, respectively [60]. When analysed individually for Types 1, 2 and 3 SMA, another study found that the total cost of home modification in the prior 12 months per patient was highest for patients with Type 2 SMA (€14,942.46), decreasing for patients with Type 3 SMA $(€ 10,796.57)$ and Type 1 SMA (€5485.84) [75]. Two studies [59, 71] provided combined costs for home and vehicle modifications according to SMA type. Both studies found that vehicle and home modifications were lowest for patients with Type 3 SMA [59, 71], but differed according to whether patients with Type 1 SMA [59] or Type 2 SMA [71] incurred the highest costs for these modifications.

\subsection{Indirect Costs}

Only 14 studies reported indirect costs (results from 13 studies are presented in Table 3). A Swedish resource use study estimated that annual costs associated with lost productivity were $€ 44,957.52$ for caregivers of patients with infantile-onset SMA, $€ 11,520.33$ for caregivers of patients with 


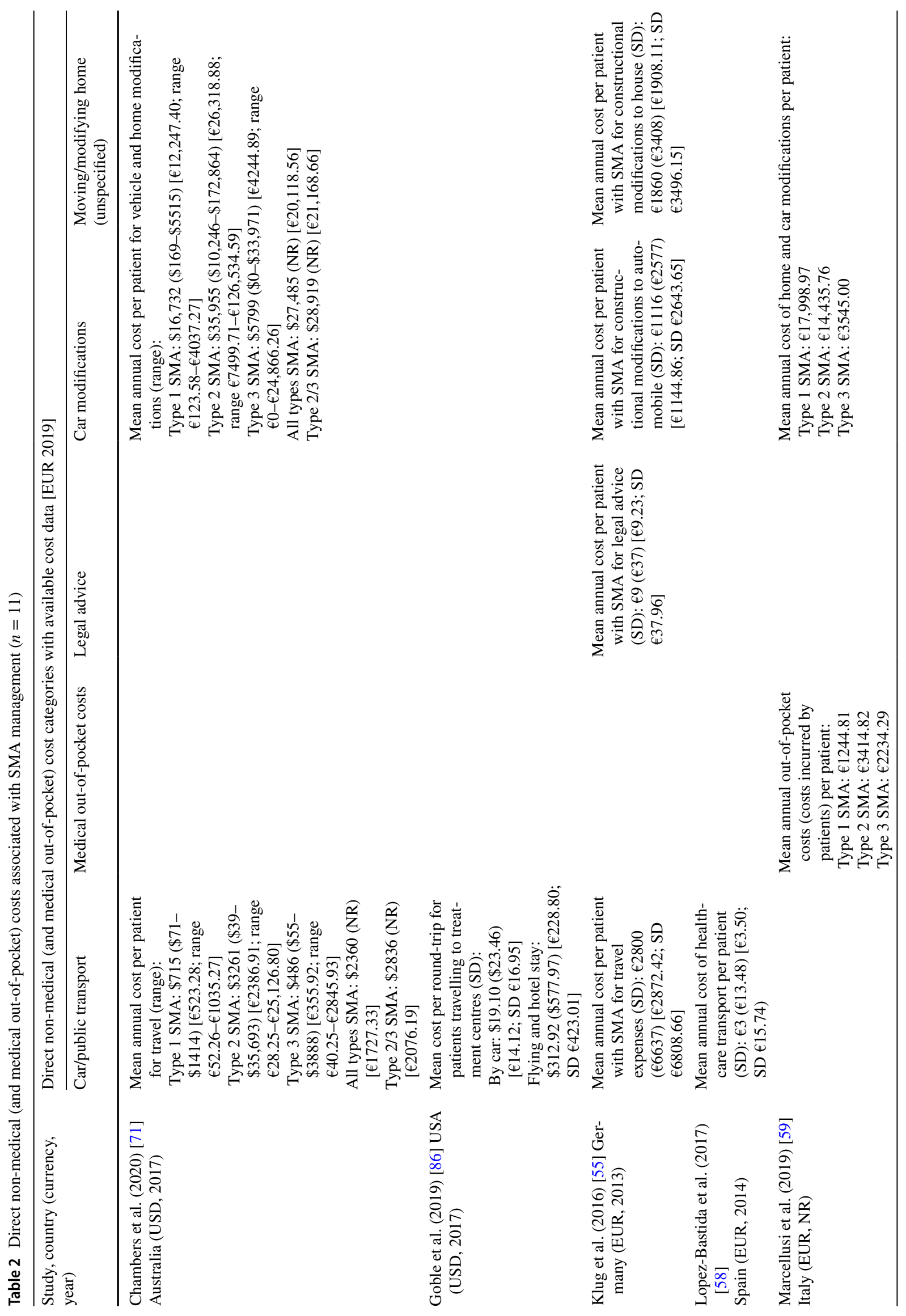




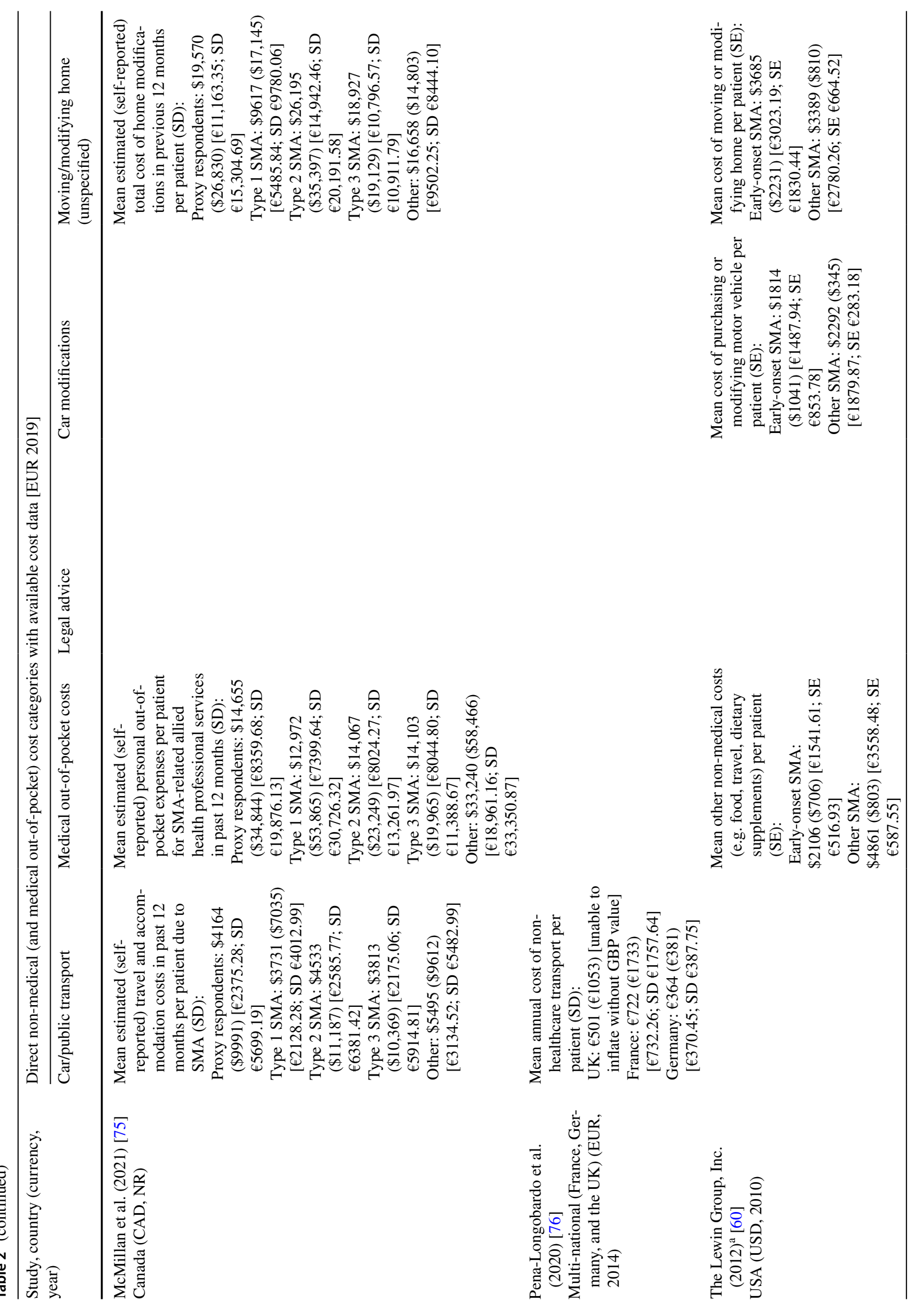




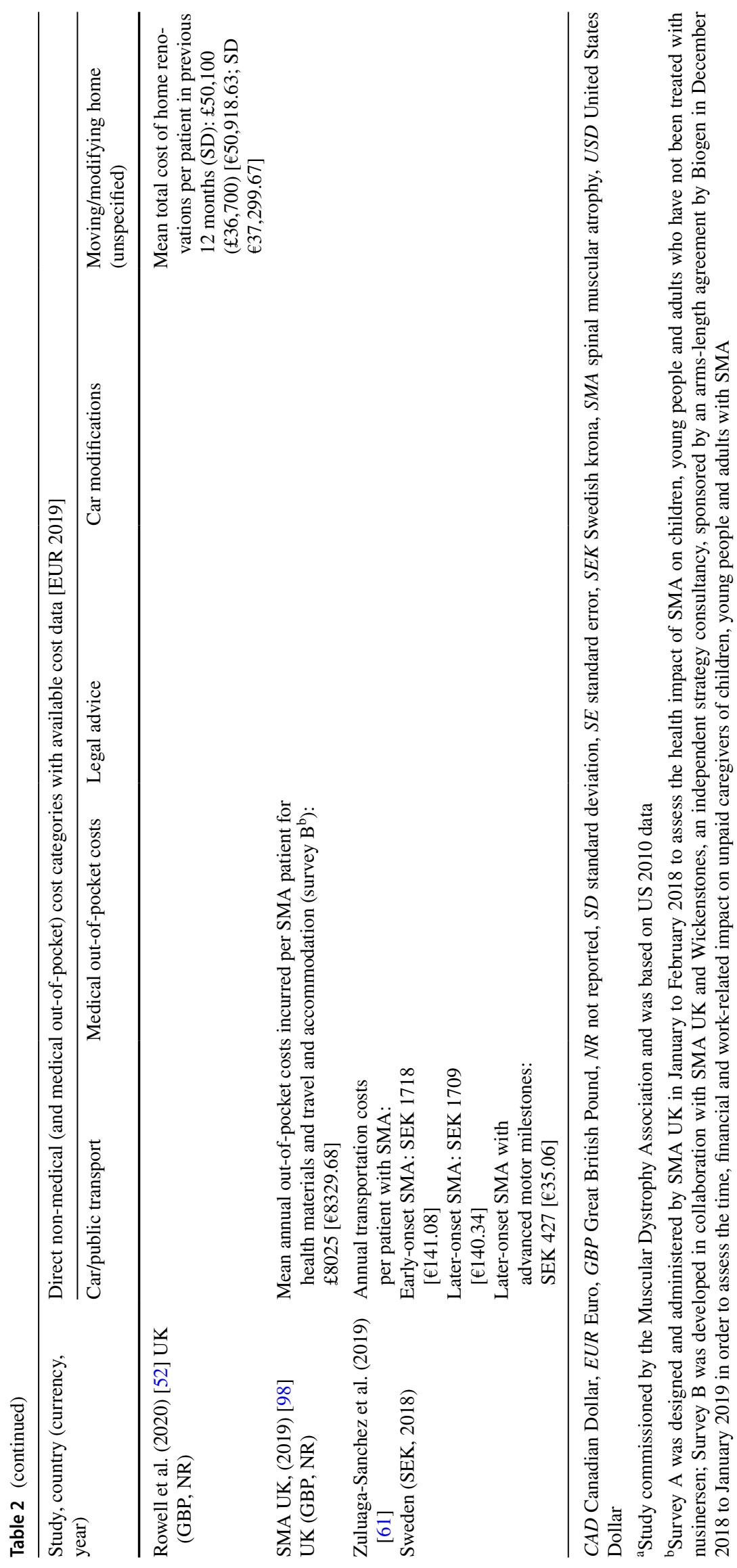


later-onset SMA and $€ 2880.12$ for caregivers of patients with later-onset SMA with advanced motor milestones [61]. In addition, one study reported costs associated with absenteeism, presenteeism and unemployment, and caregiver absenteeism and unemployment, which amounted to an annual indirect cost per patient of $€ 13,053.55, € 10,731.73$ and $€ 9522.03$ for Types 1, 2 and 3 SMA, respectively [59].

The remaining studies that reported indirect costs were primarily associated with informal care, which was a substantial burden on patients and families in terms of both cost and time. Informal care provided by family members or caregivers was reported to result in a mean annual loss of productivity cost per unpaid caregiver of $€ 14,894.82$, based on reducing their working hours by $25 \mathrm{~h}$ per week [98]. More weekly unpaid caregiving hours were noted for patients with SMA who were able to sit and roll independently, those able to sit without support but cannot roll, and those unable to sit without support (Fig. 2). These findings indicate that informal care costs are higher for individuals with Type 2 SMA compared with Type 3 SMA [98]. A study in Australia conducted before DMTs were available reported that the mean annual cost for informal care was $€ 24,803$.41 for Type 2 SMA, decreasing for patients with Type 1 SMA $(€ 20,694.10)$ and Type 3 SMA (€9353.45) [71]. Substantial informal care costs have been reported for patients with Type 1 SMA as these patients require the highest level of care [55]. Two linked studies assessed the burden of SMA on informal caregivers across three countries in Europe [69, 76]. Informal caregivers spent a daily average of $12.50 \mathrm{~h}$, $10.65 \mathrm{~h}$ and $9.31 \mathrm{~h}$ in the UK, France and Germany, respectively, attending to a patient with SMA [76], and caregivers had a 3.63-point higher likelihood of spending $>10 \mathrm{~h}$ a day providing care if the patients had Type 1 SMA compared with Type 3 SMA [69]. Collectively, the indirect cost data analysed in this review demonstrate the major burden, time given to care and loss of hourly pay experienced by caregivers of patients with SMA.

\subsection{Cost Drivers}

Cost drivers (factors that create or drive the cost of management) associated with SMA were reported in 28 studies [50, 53-61, 64, 68, 70-79, 83-85, 92, 94, 97]. Major cost drivers included the requirement for inpatient care $(n=22)$ [50, $53-56,58,60,68,70-74,76-79,84,85,92,94,97]$, use of outpatient services or specialist visits $(n=16)[50,53-55$, $58-60,70-74,76,78,84,85]$, respiratory care $(n=10)$ [50, $54,55,57,61,70,71,73,78,83]$, rehabilitation $(n=4)$ [50, $55,79,97]$, orthopaedic care $(n=2)[61,83]$, prescription costs (excluding DMT-related costs) $[n=8][50,53,58,60$, $74,76,77,84]$, home stays $(n=3)$ [58, 70, 79] and structural changes to the house or car $(n=6)[55,59,60,64,71,75]$. One study reported cost drivers to be type dependent, with
Type 1 SMA costs driven by respiratory care, and Types 2 and 3 SMA costs driven by orthopaedic care [83]. The impact of non-medical costs on the socioeconomic burden of SMA and any proxy costs on disability in general were not examined further in this review.

\subsection{Quality Assessment and Study Limitations}

Quality assessment of eligible studies was performed using the checklist adapted to cost of illness by Molinier et al. [44]. Implementation of this checklist revealed that the studies generally had clearly described objectives and methods and well-presented results as shown in Table 5 (original search) and Table 6 (update search) of the ESM. However, a sensitivity analysis to test the robustness of findings was rarely conducted. Limitations of individual studies included: (1) small sample sizes because of the rarity of the disease ( $n$ = 11) $[50,58-60,62,64,65,68,69,76,77]$; (2) potential biases and inability to adjust for confounding factors in retrospective and cross-sectional study designs $(n=5)[55$, $58,65,68,76]$; (3) potential underestimation of costs due to consideration of indirect costs only or restriction of costs to a particular setting, such as a hospital $(n=7)[50,53,54$, 59, 68, 74, 77]; (4) inherent limitations of claims databases including the potential for coding errors and other inaccuracies $(n=9)$ [50, 53, 56, 60, 70, 72, 73, 77, 78]; (5) limited generalisability of results beyond study settings, i.e. to different countries and healthcare systems $(n=5)$ [50, 53, 64, $70,77],(6)$ reliance of self-reported data, which may lead to potential recall or response bias $(n=4)[52,58,69,75]$; (7) potential selection bias due to recruitment of patients via advocacy groups or organisations $(n=4)[52,55,58,76]$; and (8) estimates calculated before approval of nusinersen; therefore, estimates may not be reflective of patients treated with this DMT $(n=1)$ [54].

\section{Discussion}

\subsection{Overall Costs of SMA}

Overall, a total of 51 publications covering 49 unique studies in SMA were identified for inclusion in this SLR. Reported costs varied broadly between studies; for example, the annual mean inpatient hospitalisation cost for patients with Type 1/early-onset SMA ranged from $€ 13,536$ [79] to $€ 76,935$ [54]. However, for later-onset SMA/Types 2 and 3 SMA, reported cost ranges were more similar, for example, from $€ 6696$ to [60] to $€ 8991$ [79]. Significantly higher all-cause mean outpatient costs for infants with SMA (€3006.24) compared with matched infants without SMA $(€ 166.66)$ were reported by one US study included in this review [84]. Collectively, the evidence reviewed in this SLR demonstrates 


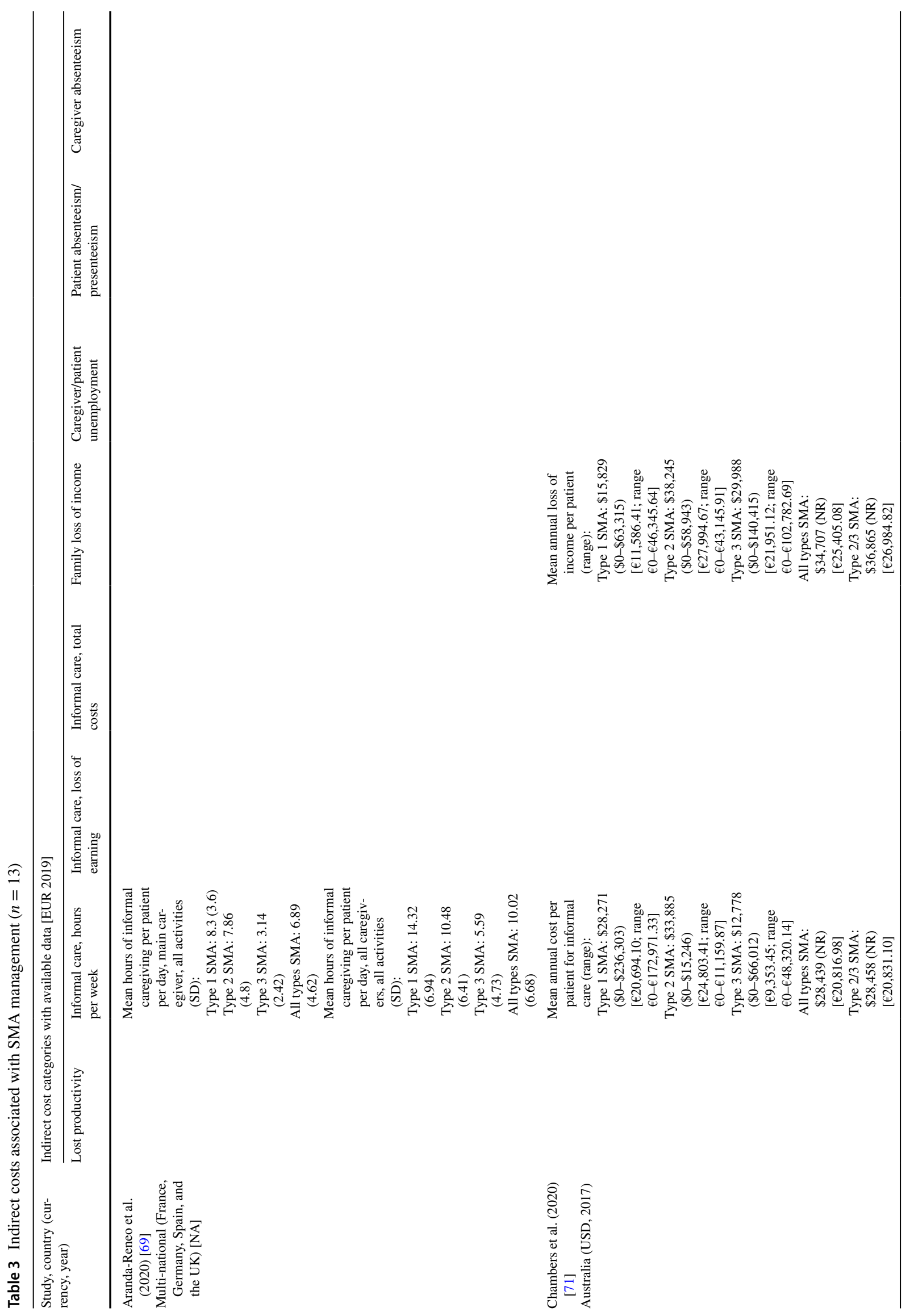




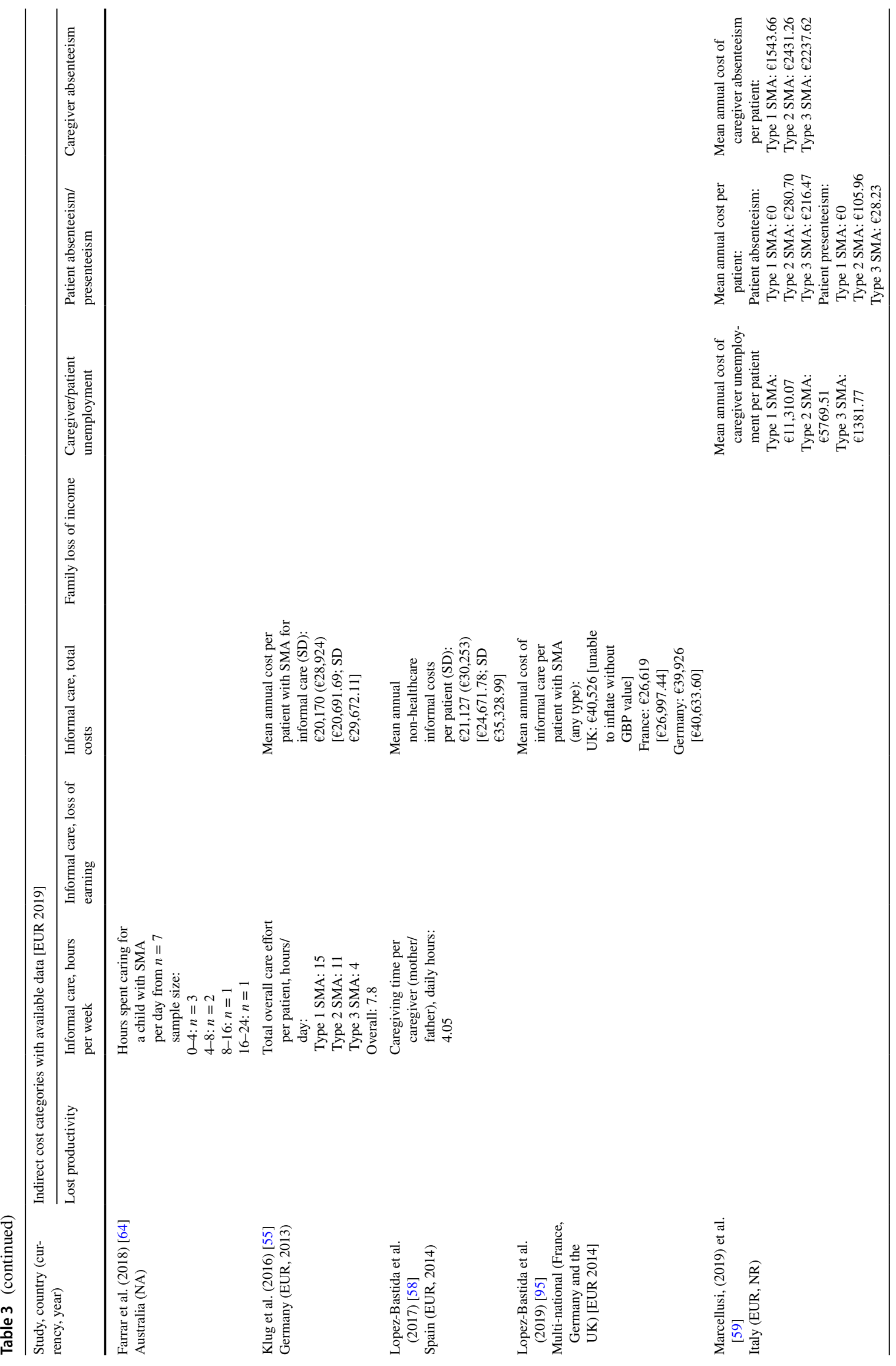

$\triangle$ Adis 


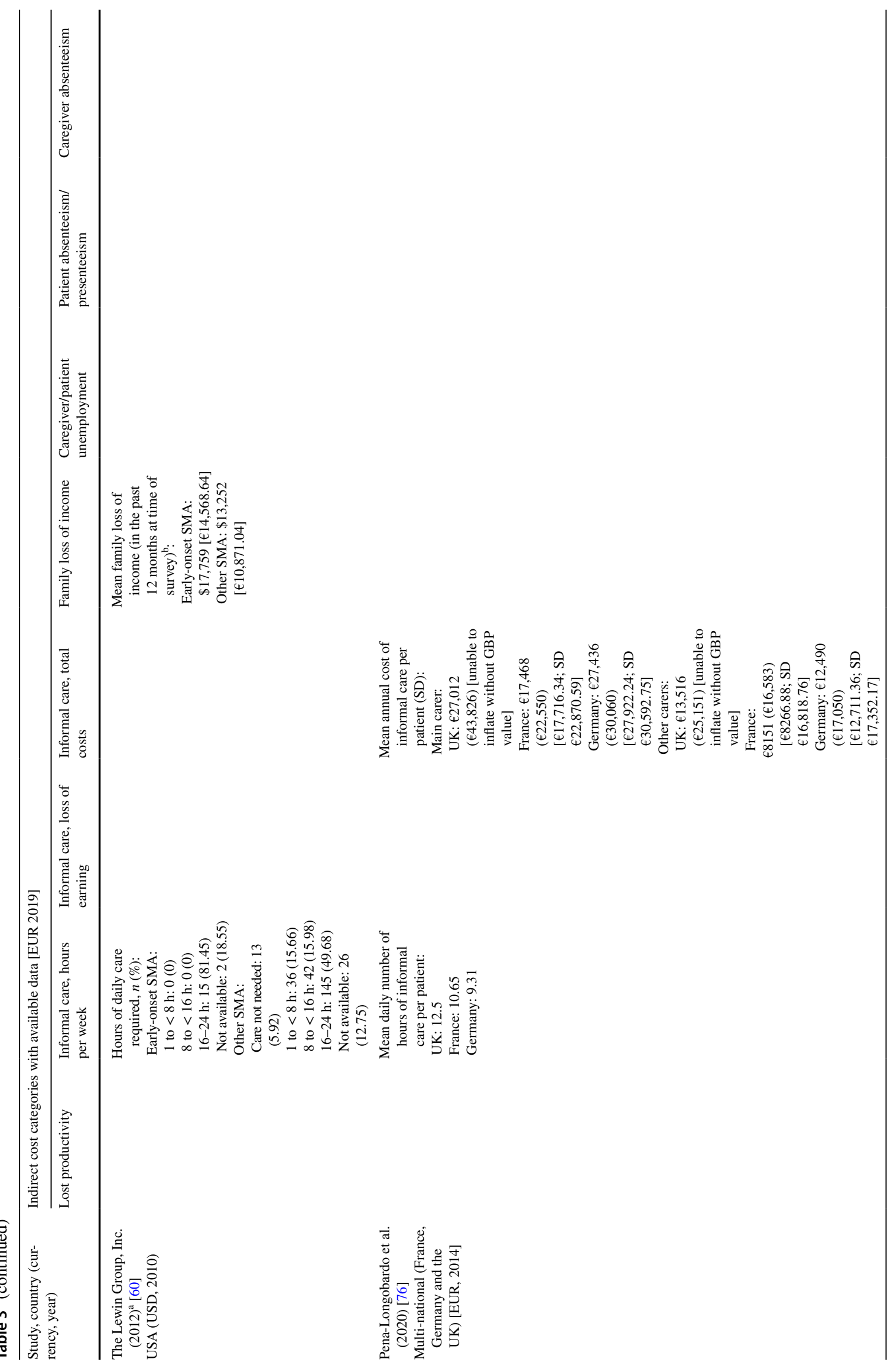




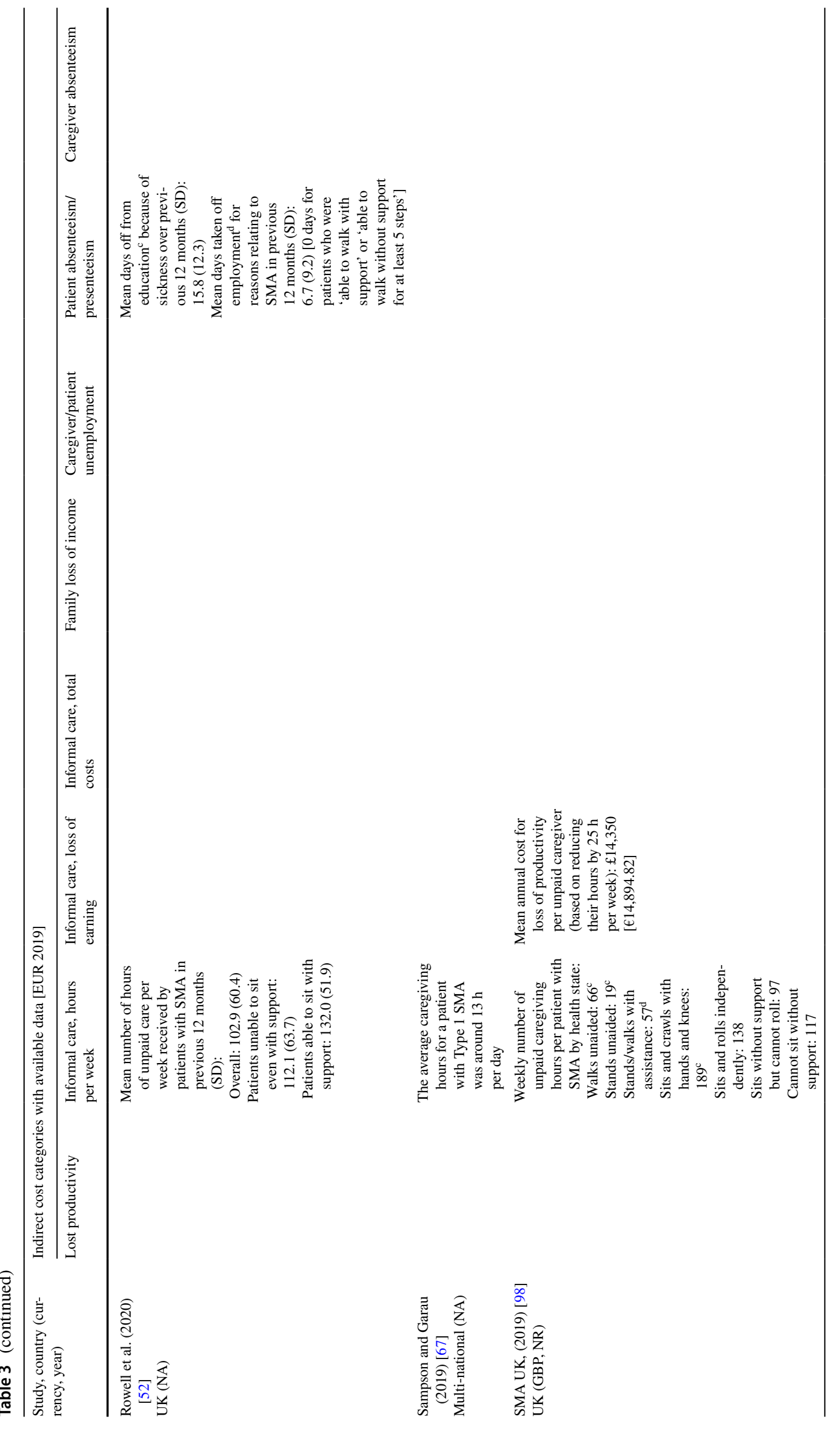

$\Delta$ Adis 


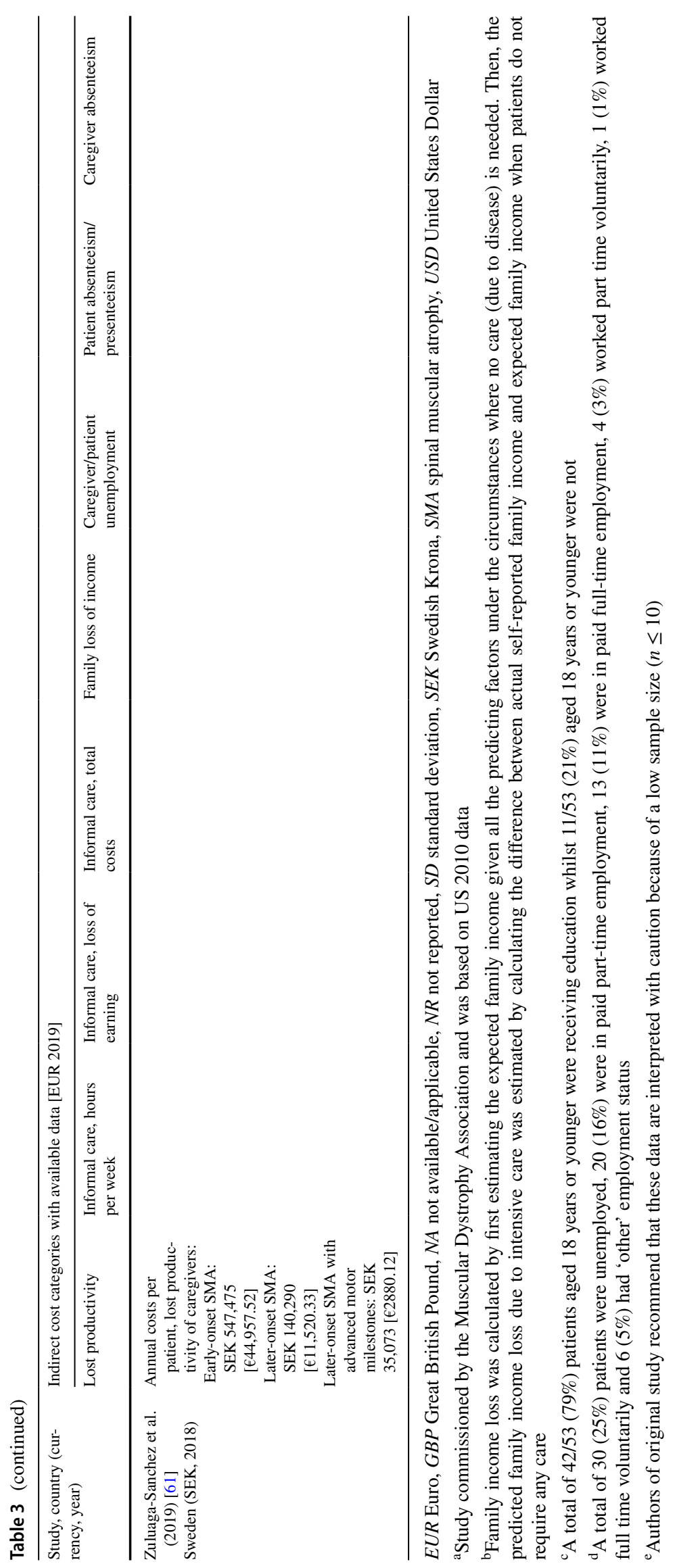




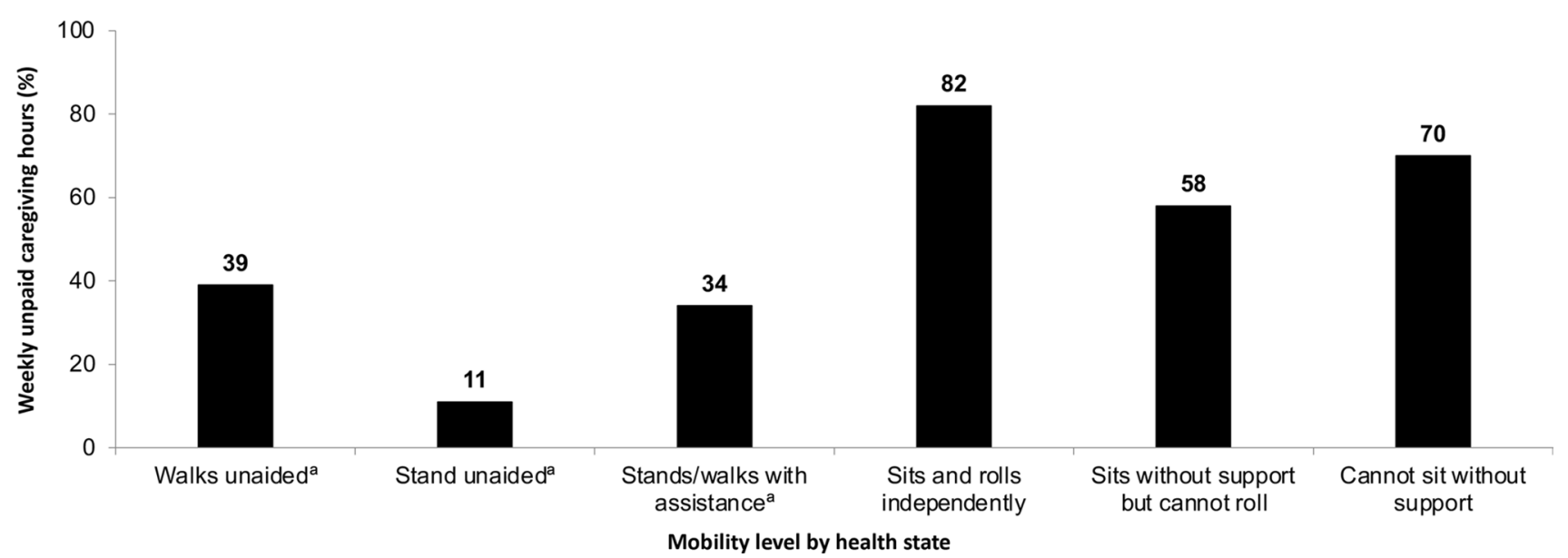

Fig. 2 Percentage of weekly unpaid caregiving hours per patient with spinal muscular atrophy according to moblity level ${ }^{\mathrm{b}}$. ${ }^{\mathrm{a}}$ Small sample size $(\leq 10) ;{ }^{\text {b}}$ Adapted from SMA UK [98]

that SMA causes a significant burden to patients, caregivers and healthcare systems, although the extent of the burden is dependent on the type of SMA reported.

In studies that reported SMA type, most studies considered patients with Type 1 SMA $(n=11)$, reporting higher annual costs and resource use because of the level of upfront care required by patients compared with Type 2 or 3 SMA. Three studies described the highest mean annual direct cost for patients with Type 1 SMA and found that this cost progressively decreased in Types 2 and 3 SMA [55, 71, 83]. The authors of one of the studies mentioned that given the differential life expectancy by SMA type, patients with Types 2 and 3 SMA are likely to incur higher lifetime costs compared with patients with Type 1 SMA [83]. However, it should be noted that with new therapies now available, the life expectancy of patients with SMA is increasing [29], which is likely to affect the cost associated with Type 1 SMA in the near future.

In contrast to direct costs, indirect costs were found to vary by SMA type (Type 1, €47,145.66; Type 2, €60,122.84; and Type 3, €27,636.79 per annum) [55]. Patients who may not incur high direct healthcare costs from treatment have a cost-of-illness burden that is commonly affected by caregiver absenteeism and loss of work productivity [55]. The mean annual cost of caregiver absenteeism was highest for patients with Type 2 (€2431.26), followed by Type 3 (€2237.62) and Type 1 (€1543.66) SMA [59]. Of households of children with Type 1, 2 or 3 SMA in Australia, $56 \%$ of total costs were attributed to direct costs, and the average total indirect healthcare costs were highest for households with a child with Type 2 SMA [71]. However, the mean annual cost associated with caregiver unemployment was highest for patients with Type 1 (€11,310.07), followed by Type 2 (€5769.51) and Type 3 (€1381.77) SMA [59]. Major cost drivers also included inpatient care, outpatient services, specialist visits, respiratory care, rehabilitation and prescription costs. Cost drivers were dependent on SMA type; for patients with Type 1 SMA, this was mainly due to respiratory care, whereas in patients with Types 2 and 3 SMA, the main cost driver was orthopaedic care [83].

\subsection{Limitations of Individual Studies Identified in this SLR}

The findings from this SLR should be considered in the context of the individual study caveats. For instance, one study was presented as a slide deck. Data were obtained from two unpublished surveys conducted in the UK that were not peer reviewed and indeed the survey authors highlighted that the results should therefore be interpreted with caution. In addition, 35 studies were retrospective analyses, and 11 studies enrolled relatively small patient samples [50, 58-60, 62, 64, $65,68,69,76,77]$. Conference abstracts comprised $45 \%$ of the publications that met the eligibility criteria for the SLR; therefore, limited reporting makes robust interpretation and quality assessment of these data challenging. Clinical trials reporting resource use data as secondary outcomes were not included in this SLR, as the primary aim of those trials was not to assess costs and resource use in SMA.

This SLR highlights several data gaps in the current published literature. As SMA is a rare disease, studies of the cost and burden of SMA on patients, caregivers and society at large are limited. In particular, there is a paucity of robust evidence relating to the indirect costs associated with SMA. In addition, no studies describing relevant outcomes of interest distinctly for patients with Type 4 SMA were identified, likely because this demographic has the mildest form of the disease and these patients do not typically present with symptoms until their second or third decade [9]. Where data from patients with Type 4 SMA were included, 
these data were typically combined with Types 2 and 3 SMA data in a later-onset SMA cohort or were included in a study of adult patients with SMA. Limited cost and resource use data were also available for professional caregiving, surgical procedures, tests and examinations, complications and palliative care.

\subsection{Implications for Future Assessments of Cost and Resource Use in SMA}

This review highlights the cost and resource use associated with SMA and strongly suggests that they are dependent on SMA type. Despite the trend of SMA type association with costs, direct data comparisons between studies were challenging because of the heterogeneity of the data reported. Interestingly, the studies examined in this review did not assess the cost and resource use associated with SMA by motor function. Considering that motor function can vary broadly, especially in Type 2 SMA, it would be beneficial to understand how cost and resource use are affected by different degrees of ambulation, or generally by different motor function levels, for example, sitters/non-sitters and patients who can stand or walk. Reporting SMA severity by motor function would harmonise global data and would be consistent with SMA management. This approach would complement emerging evidence of a phenotypic overlap between SMA types that has led to recommendations that the traditional classification of SMA should be revised, in favour of descriptive terms of the mobility status of individuals that better reflect the continuum of disease [100, 101].

Two recently published SLRs on the cost associated with SMA describe the exceptional cost burden of standard of care for patients with SMA [102, 103]. In agreement with the current SLR findings, Type 1 SMA was associated with the highest annual direct medical costs, although cost ranges varied from the current SLR because of different inclusion criteria [102, 103]. For a rare disease such as SMA, SLRs provide valuable knowledge of cost and resource use that is urgently needed to aid decisions about resource use allocation. Recently, the cost burden of SMA has been estimated to be 54.2 times greater for patients with SMA compared with a healthy population, with a predicted $\$ 4-\$ 5$ million cost for patients with early-onset SMA over a 10-year period [104].

\subsection{Consideration of Treatment with DMTs for Future Assessments of Cost and Resource Use in SMA}

Given the approvals for nusinersen, onasemnogene abeparvovec and risdiplam, treatment costs will need to be considered in future assessments. Preliminary data from studies included in this SLR have indicated that treatment with DMTs has a positive effect on costs and resource use associated with SMA; however, long-term follow-up data are currently lacking. Treatment with DMTs has led to longer survival for patients with Type 1 SMA and a clinically meaningful improvement in patients with early-onset and later-onset SMA [105-111]. In addition to the cost of DMTs, future economic evaluations should consider the shifts in costs that will occur between cost categories and between the healthcare system and patients and their caregivers. For example, DMT treatment for patients with Type 1 SMA may reduce acute hospitalisation and permanent ventilation costs, whereas the use of other, less invasive respiratory support aids may increase. For patients with SMA who achieve better motor function as a result of treatment with DMTs, indirect costs may increase because of the introduction of new mobility equipment. Important cost considerations include the comorbidities associated with SMA. For example, one study included in this SLR [73] found that $71.26 \%$ of patients with SMA had chronic conditions that affected four or more body systems. Recent research has identified several non-neuromuscular clinical signs, affecting the cardiovascular, gastrointestinal, metabolic, reproductive and skeletal systems, which manifest prior to clinical signs of neuromuscular degeneration [40]. Treatment approaches to mitigate the severity of non-neuromuscular conditions may also change the natural course of SMA progression and contribute to cost and resource use savings. A long-term wholebody approach, potentially including both SMN-dependent and SMN-independent therapies, should be considered for SMA management [101].

A cost associated with SMA that should also be considered in future studies is newborn screening (NBS), especially in the USA following the recent addition of SMA to the Recommended Uniform Screening Panel for newborns. NBS for SMA that detects the exon 7 deletion in SMN1 should identify at least $95 \%$ of SMA cases $[112,113]$, and early treatment should slow disease progression [114]. Even though early detection would potentially extend treatment duration (with the exception of one-time administration of onasemnogene abeparvovec), DMTs for SMA are most likely to be effective if initiated before patients become symptomatic, leading to reduced costs and resource use over the long term. While limited follow-up data of DMTs are currently available, NBS will increase access to treatments that can be initiated within a short time [113], which is important because of the developmental component and severity of SMA. In addition to identification of SMN1 deletion in NBS for SMA, laboratory analyses also usually determine the number of $S M N 2$ copies of a newborn [115], which is inversely correlated to disease severity $[5,116]$. Therefore, $S M N 2$ copy number as a predictor of clinical disease and a tool to identify individuals who may benefit most from DMTs [117] could be factored into treatment plans following 
NBS. It should be noted, however, that $S M N 2$ copy number determination from NBS does not definitively predict disease severity, and discordant results between the SMN2 copy number and the SMA phenotype arising from genetic analysis are described $[115,118]$. Questions have been raised regarding the timing of commencing DMTs in cases of SMA identified at birth but for whom clinical signs may not present until adulthood [114], for example, with patients with a higher $S M N 2$ copy number. Failure to begin DMT use in the landscape of improved treatment options could lead to an increase in costs for patients who initiate treatment only when symptomatic. These patients may subsequently require long-term multi-disciplinary care because of motor neuron function that has already been irreversibly lost [112].

\section{Conclusions}

The economic burden of SMA is substantial to patients, caregivers and the health service, especially when compared with the general population. Even though SMA is a monogenic disorder, SMA types are associated with different, yet all high, cost-of-illness burdens. Long-term robust studies are required to fully elucidate the economic burden of SMA, particularly regarding indirect costs and data for patients with Type 4 SMA. As patients with Type 1 SMA are now living longer and have better outcomes following treatment with DMTs, a new understanding of the cost burden of SMA should be assessed for these patients and is relevant for DMT improvements provided in Types 2 and 3 SMA. Differentiating data in terms of motor function may also be beneficial to determine long-term improvements aided by DMTs compared with natural history in untreated patients. Global, regional and/or local data collection platforms and disease registry networks could play an important role in helping to address these current data gaps. Cost and resource studies should also incorporate the patient/caregiver perspective to better understand the cost of burden, and most importantly, which factors (direct and/or indirect costs and resource use) impact quality of life the most for patients with SMA.

Supplementary Information The online version contains supplementary material available at https://doi.org/10.1007/s40273-021-01105-7.

Acknowledgements The authors thank Rosalind Carney, DPhil, of MediTech Media Ltd for providing medical writing support, which was funded by F. Hoffmann-La Roche Ltd, Basel, Switzerland in accordance with Good Publication Practice (GPP3) guidelines (http://www. ismpp.org/gpp3).

\section{Declarations}

Funding This study was funded by F. Hoffmann-La Roche Ltd, Basel, Switzerland.
Conflicts of interest/Competing interests During the preparation of this manuscript, C. Simone Sutherland was employed by F. HoffmannLa Roche and owns stocks in Roche. During the preparation of this manuscript, Noman Paracha was employed by F. Hoffmann-La Roche and owns stocks in Roche. Pollyanna Hudson's and Stephen Mitchell's employer, Mtech Access, was commissioned by Roche, and therefore received a consulting fee to conduct the systematic review presented in the manuscript.

Disclosure This article is published in a special edition journal supplement wholly funded by F. Hoffmann-La Roche Ltd.

Ethics approval Not applicable.

Consent to participate Not applicable.

Consent for publication Not applicable.

Availability of data and material Not applicable.

Code availability Not applicable.

Author contributions NP and CSS conceptualised the study and all authors contributed to the study design. PH and SM conducted the literature search, data extraction, initial summary of results and quality assessment. All authors contributed to data interpretation and development of the manuscript, including the figures, tables and online resource materials. All authors approved the final version of the manuscript.

Open Access This article is licensed under a Creative Commons Attribution-NonCommercial 4.0 International License, which permits any non-commercial use, sharing, adaptation, distribution and reproduction in any medium or format, as long as you give appropriate credit to the original author(s) and the source, provide a link to the Creative Commons licence, and indicate if changes were made. The images or other third party material in this article are included in the article's Creative Commons licence, unless indicated otherwise in a credit line to the material. If material is not included in the article's Creative Commons licence and your intended use is not permitted by statutory regulation or exceeds the permitted use, you will need to obtain permission directly from the copyright holder. To view a copy of this licence, visit http://creativecommons.org/licenses/by-nc/4.0/.

\section{References}

1. Verhaart IEC, Robertson A, Wilson IJ, Aartsma-Rus A, Cameron S, Jones CC, et al. Prevalence, incidence and carrier frequency of 5q-linked spinal muscular atrophy: a literature review. Orphanet J Rare Dis. 2017;12(1):124. https://doi.org/10.1186/ s13023-017-0671-8.

2. Wirth B. An update of the mutation spectrum of the survival motor neuron gene (SMN1) in autosomal recessive spinal muscular atrophy (SMA). Hum Mutat. 2000;15(3):228-37. https:// doi.org/10.1002/(SICI)1098-1004(200003)15:3\%3c228::AIDHUMU3\%3e3.0.CO;2-9.

3. Kolb SJ, Kissel JT. Spinal muscular atrophy. Neurol Clin. 2015;33(4):831-46. https://doi.org/10.1016/j.ncl.2015.07.004.

4. Lorson CL, Hahnen E, Androphy EJ, Wirth B. A single nucleotide in the SMN gene regulates splicing and is responsible for spinal muscular atrophy. Proc Natl Acad Sci USA. 1999;96(11):6307-11. https://doi.org/10.1073/pnas.96.11.6307. 
5. Crawford TO, Paushkin SV, Kobayashi DT, Forrest SJ, Joyce CL, Finkel RS, et al. Evaluation of SMN protein, transcript, and copy number in the biomarkers for spinal muscular atrophy (BforSMA) clinical study. PLoS ONE. 2012;7(4): e33572. https://doi.org/10.1371/journal.pone.0033572.

6. Feldkotter M, Schwarzer V, Wirth R, Wienker TF, Wirth B. Quantitative analyses of SMN1 and SMN2 based on real-time lightCycler PCR: fast and highly reliable carrier testing and prediction of severity of spinal muscular atrophy. Am J Hum Genet. 2002;70(2):358-68. https://doi.org/10.1086/338627.

7. D’Amico A, Mercuri E, Tiziano FD, Bertini E. Spinal muscular atrophy. Orphanet J Rare Dis. 2011;6:71. https://doi.org/10.1186/ 1750-1172-6-71.

8. Prior TW. Perspectives and diagnostic considerations in spinal muscular atrophy. Genet Med. 2010;12(3):145-52. https://doi. org/10.1097/GIM.0b013e3181c5e713.

9. Talbot K, Tizzano EF. The clinical landscape for SMA in a new therapeutic era. Gene Ther. 2017;24(9):529-33. https://doi.org/ 10.1038/gt.2017.52.

10. Mercuri E, Bertini E, Iannaccone ST. Childhood spinal muscular atrophy: controversies and challenges. Lancet Neurol. 2012;11(5):443-52. https://doi.org/10.1016/S1474-4422(12) 70061-3.

11. Finkel RS, Mercuri E, Meyer OH, Simonds AK, Schroth MK, Graham RJ, et al. Diagnosis and management of spinal muscular atrophy: Part 2: Pulmonary and acute care; medications, supplements and immunizations; other organ systems; and ethics. Neuromuscul Disord. 2018;28(3):197-207. https://doi.org/10. 1016/j.nmd.2017.11.004.

12. Mercuri E, Finkel RS, Muntoni F, Wirth B, Montes J, Main M, et al. Diagnosis and management of spinal muscular atrophy: Part 1: recommendations for diagnosis, rehabilitation, orthopedic and nutritional care. Neuromuscul Disord. 2018;28(2):103-15. https://doi.org/10.1016/j.nmd.2017.11.005.

13. Wan HWY, Carey KA, D'Silva A, Vucic S, Kiernan MC, Kasparian NA, et al. Health, wellbeing and lived experiences of adults with SMA: a scoping systematic review. Orphanet J Rare Dis. 2020;15(1):70. https://doi.org/10.1186/s13023-020-1339-3.

14. Wang CH, Finkel RS, Bertini ES, Schroth M, Simonds A, Wong $\mathrm{B}$, et al. Consensus statement for standard of care in spinal muscular atrophy. J Child Neurol. 2007;22(8):1027-49. https://doi. org/10.1177/0883073807305788.

15. Dubowitz V. Very severe spinal muscular atrophy (SMA type 0): an expanding clinical phenotype. Eur J Paediatr Neurol. 1999;3(2):49-51. https://doi.org/10.1053/ejpn.1999.0181.

16. Munsat TL, International SMA. Collaboration. Neuromuscul Disord. 1991;1(2):81. https://doi.org/10.1016/0960-8966(91) 90052-T.

17. Munsat TL, Davies KE. In: International SMA consortium meeting. (26-28 June 1992, Bonn, Germany). Neuromuscul Disord. 1992;2(5-6):423-8. doi: https://doi.org/10.1016/s0960-8966(06) 80015-5.

18. Verhaart IEC, Robertson A, Leary R, McMacken G, Konig $\mathrm{K}$, Kirschner J, et al. A multi-source approach to determine SMA incidence and research ready population. J Neurol. 2017;264(7):1465-73. https://doi.org/10.1007/ s00415-017-8549-1.

19. Lally C, Jones C, Farwell W, Reyna SP, Cook SF, Flanders WD. Indirect estimation of the prevalence of spinal muscular atrophy Type I, II, and III in the United States. Orphanet J Rare Dis. 2017;12(1):175. https://doi.org/10.1186/s13023-017-0724-z.

20. US Food and Drug Administration. Spinraza ${ }^{\circledR}$ (nusinersen) [package insert]. Cambridge: Biogen Inc.; 2016.

21. European Medicines Agency. Spinraza. 2017. https://www.ema. europa.eu/en/medicines/human/EPAR/spinraza. Accessed 6 Nov 2020 .
22. US Food and Drug Administration. Zolgensma ${ }^{\circledR}$ (onasemnogene abeparvovec-xioi) [package insert]. Bannockburn: AveXis Inc.; 2019.

23. European Medicines Agency. Zolgensma. 2020. https://www. ema.europa.eu/en/medicines/human/EPAR/zolgensma. Accessed 17 Oct 2021.

24. US Food and Drug Administration. EvrysdiTM (risdiplam) [package insert]. South San Francisco: Genentech Inc.; 2020.

25. European Medicines Agency. Risdiplam. 2021. https://www.ema. europa.eu/en/medicines/human/EPAR/evrysdi. Accessed 5 May 2021.

26. Hua Y, Sahashi K, Hung G, Rigo F, Passini MA, Bennett CF, et al. Antisense correction of SMN2 splicing in the CNS rescues necrosis in a type III SMA mouse model. Genes Dev. 2010;24(15):1634-44. https://doi.org/10.1101/gad.1941310.

27. Mendell JR, Al-Zaidy S, Shell R, Arnold WD, Rodino-Klapac LR, Prior TW, et al. Single-dose gene-replacement therapy for spinal muscular atrophy. N Engl J Med. 2017;377(18):1713-22. https://doi.org/10.1056/NEJMoa1706198.

28. Ratni H, Ebeling M, Baird J, Bendels S, Bylund J, Chen KS, et al. Discovery of risdiplam, a selective survival of motor neuron-2 (SMN2) gene splicing modifier for the treatment of spinal muscular atrophy (SMA). J Med Chem. 2018;61(15):6501-17. https://doi.org/10.1021/acs.jmedchem.8b00741.

29. Schorling DC, Pechmann A, Kirschner J. Advances in treatment of spinal muscular atrophy: new phenotypes, new challenges, new implications for care. J Neuromuscul Dis. 2020;7(1):1-13. https://doi.org/10.3233/JND-190424.

30. Gusset N, Stalens C, Stumpe E, Klouvi L, Mejat A, Ouillade $\mathrm{MC}$, et al. Understanding European patient expectations towards current therapeutic development in spinal muscular atrophy. Neuromuscul Disord. 2021. https://doi.org/10.1016/j.nmd.2021.01. 012.

31. Messina S, Sframeli M. New treatments in spinal muscular atrophy: positive results and new challenges. J Clin Med. 2020;9(7):2222. https://doi.org/10.3390/jcm9072222.

32. Glanzman AM, Mazzone E, Main M, Pelliccioni M, Wood J, Swoboda KJ, et al. The Children's Hospital of Philadelphia Infant Test of Neuromuscular Disorders (CHOP INTEND): test development and reliability. Neuromuscul Disord. 2010;20(3):155-61. https://doi.org/10.1016/j.nmd.2009.11.014.

33. Haataja L, Mercuri E, Regev R, Cowan F, Rutherford M, Dubowitz V, et al. Optimality score for the neurologic examination of the infant at 12 and 18 months of age. J Pediatr. 1999;135(2 Pt 1):153-61. https://doi.org/10.1016/s0022-3476(99)70016-8.

34. Glanzman AM, O'Hagen JM, McDermott MP, Martens WB, Flickinger J, Riley S, et al. Validation of the expanded hammersmith functional motor scale in spinal muscular atrophy type II and III. J Child Neurol. 2011;26(12):1499-507. https://doi.org/ 10.1177/0883073811420294.

35. Mazzone ES, Mayhew A, Montes J, Ramsey D, Fanelli L, Young SD, et al. Revised upper limb module for spinal muscular atrophy: development of a new module. Muscle Nerve. 2017;55(6):869-74. https://doi.org/10.1002/mus.25430.

36. A.T.S. Committee on proficiency standards for clinical pulmonary function laboratories. ATS statement: guidelines for the sixminute walk test. Am J Respir Crit Care Med. 2002;166(1):1117. https://doi.org/10.1164/ajrccm.166.1.at1102.

37. Bayley N. Bayley scales of infant and toddler development ${ }^{\circledR} 3 \mathrm{rd}$ edition (Bayley-III ${ }^{\circledR}$ ). San Antonio: The Psychological Corporation; 2006.

38. Berard C, Payan C, Hodgkinson I, Fermanian J, Group MFMCS. A motor function measure for neuromuscular diseases: construction and validation study. Neuromuscul Disord. 2005;15(7):46370. https://doi.org/10.1016/j.nmd.2005.03.004. 
39. Lin CW, Kalb SJ, Yeh WS. Delay in diagnosis of spinal muscular atrophy: a systematic literature review. Pediatr Neurol. 2015;53(4):293-300. https://doi.org/10.1016/j.pediatrneurol. 2015.06.002.

40. Lipnick SL, Agniel DM, Aggarwal R, Makhortova NR, Finlayson SG, Brocato A, et al. Systemic nature of spinal muscular atrophy revealed by studying insurance claims. PLoS ONE. 2019;14(3): e0213680. https://doi.org/10.1371/journal.pone.0213680.

41. Gusset N, Erbas Y, Germanenko O, Rucinski K, Stumpe E, de Lemus M. A decision for life: treatment decisions in newly diagnosed families with spinal muscular atrophy (SMA). Eur J Paediatr Neurol. 2020;S1090-3798(20):30220-8. https://doi.org/10. 1016/j.ejpn.2020.11.003.

42. Page MJ, McKenzie JE, Bossuyt PM, Boutron I, Hoffmann TC, Mulrow CD, et al. The PRISMA 2020 statement: an updated guideline for reporting systematic reviews. BMJ. 2021;372: $\mathrm{n} 71$. https://doi.org/10.1136/bmj.n71.

43. Richardson WS, Wilson MC, Nishikawa J, Hayward RS. The well-built clinical question: a key to evidence-based decisions. ACP J Club. 1995;123(3):A12-3.

44. Molinier L, Bauvin E, Combescure C, Castelli C, Rebillard $\mathrm{X}$, Soulie M, et al. Methodological considerations in cost of prostate cancer studies: a systematic review. Value Health. 2008;11(5):878-85. https://doi.org/10.1111/j.1524-4733.2008. 00327.x.

45. Eurostat. Harmonised Index of Consumer Prices (HICP). https:// ec.europa.eu/eurostat/web/hicp. Accessed 16 Nov 2020.

46. US Bureau of Labor Statistics. CPI for All Urban Consumers (CPI-U). https://www.bls.gov/. Accessed 16 Nov 2020.

47. Organisation for Economic Co-Operation and Development (OECD). PPPs and exchange rates. https://stats.oecd.org/Index. aspx?DataSetCode=SNA_Table4 . Accessed 16 Nov 2020.

48. Arjunji R, Dean R, Jensen I, Miller B, Menier M, Sproule D, et al editors. Value of AVXS-101 for spinal muscular atrophy type 1: improved survival and motor function, lower use of pulmonary support with decreased hospitalization and associated costs. Hoboken: Wiley; 2019.

49. Arjunji R, Dean R, Jensen IS, Miller B, Menier M, Sproule DM, et al. PBI10 Type I spinal muscular atrophy patients treated with AVXS-101 have lower use of ventilatory support, hospitalization, and associated costs compared to those treated with nusinersen. Value Health. 2019;22:S48. https://doi.org/10.1016/j.jval.2019. 04.093.

50. Droege M, Sproule D, Arjunji R, Gauthier-Loiselle M, Cloutier M, Dabbous O. Economic burden of spinal muscular atrophy in the United States: a contemporary assessment. J Med Econ. 2020;23(1):70-9. https://doi.org/10.1080/13696998.2019.16462 63.

51. Droege M, Dabbous O, Arjunji R, Gauthier-Loiselle M, Cloutier M, Sproule D. P.062. Burden of illness of spinal muscular atrophy (SMA): an update. Can J Neurol Sci. 2019;46(s1):S30-1. https://doi.org/10.1017/cjn.2019.162.

52. Rowell J, Vincent SA, Saberian S, Scoto M, Muntoni F. PRO22. A real world study investigating the resource use and burden associated with spinal muscular atrophy (SMA) from the perspective of patients and carers in the UK. Value Health. 2020;23:S693. https://doi.org/10.1016/j.jval.2020.08.1758.

53. Armstrong EP, Malone DC, Yeh WS, Dahl GJ, Lee RL, Sicignano N. The economic burden of spinal muscular atrophy. J Med Econ. 2016;19(8):822-6. https://doi.org/10.1080/13696998. 2016.1198355

54. Cardenas J, Menier M, Heitzer MD, Sproule DM. High healthcare resource use in hospitalized patients with a diagnosis of spinal muscular atrophy type 1 (SMA1): retrospective analysis of the Kids' Inpatient Database (KID). Pharmacoecon Open. 2019;3(2):205-13. https://doi.org/10.1007/s41669-018-0093-0.
55. Klug C, Schreiber-Katz O, Thiele S, Schorling E, Zowe J, Reilich $\mathrm{P}$, et al. Disease burden of spinal muscular atrophy in Germany. Orphanet J Rare Dis. 2016;11(1):58. https://doi.org/10.1186/ s13023-016-0424-0.

56. Lee M Jr, Franca UL, Graham RJ, McManus ML. Pre-nusinersen hospitalization costs of children with spinal muscular atrophy. Pediatr Neurol. 2019;92:3-5. https://doi.org/10.1016/j.pediatrneu rol.2018.11.002.

57. Lemoine TJ, Swoboda KJ, Bratton SL, Holubkov R, Mundorff M, Srivastava R. Spinal muscular atrophy type 1: are proactive respiratory interventions associated with longer survival? Pediatr Crit Care Med. 2012;13(3):e161-5. https://doi.org/10.1097/PCC. 0b013e3182388ad1.

58. Lopez-Bastida J, Pena-Longobardo LM, Aranda-Reneo I, Tizzano E, Sefton M, Oliva-Moreno J. Social/economic costs and health-related quality of life in patients with spinal muscular atrophy (SMA) in Spain. Orphanet J Rare Dis. 2017;12(1):141. https://doi.org/10.1186/s13023-017-0695-0.

59. Marcellusi A, Bini C, Casiraghi J, D’Ambrosio F, Rotundo MA, Pallara A, et al. Cost of illness of spinal muscular atrophy (SMA) in Italy. Global Region Health Technol Assess. 2019;2019:2284240319867662

60. The Lewin Group Inc. Cost of amyotrophic lateral sclerosis, muscular dystrophy, and spinal muscular atrophy in the United States: final report. 2012. https://www.mda.org/sites/default/files/ Cost_Illness_Report.pdf. Accessed 13 Nov 2019.

61. Zuluaga-Sanchez S, Teynor M, Knight C, Thompson R, Lundqvist T, Ekelund M, et al. Cost effectiveness of nusinersen in the treatment of patients with infantile-onset and later-onset spinal muscular atrophy in Sweden. Pharmacoeconomics. 2019;37(6):845-65. https://doi.org/10.1007/ s40273-019-00769-6.

62. Chabanon A, Seferian AM, Daron A, Pereon Y, Cances C, Vuillerot $\mathrm{C}$, et al. Prospective and longitudinal natural history study of patients with Type 2 and 3 spinal muscular atrophy: baseline data NatHis-SMA study. PLoS ONE. 2018;13(7): e0201004. https://doi.org/10.1371/journal.pone.0201004.

63. Dabbous O, Maru B, Jansen JP, Lorenzi M, Cloutier M, Guerin A, et al. Survival, motor function, and motor milestones: comparison of AVXS-101 relative to nusinersen for the treatment of infants with spinal muscular atrophy Type 1. Adv Ther. 2019;36(5):1164-76. https://doi.org/10.1007/ s12325-019-00923-8.

64. Farrar MA, Carey KA, Paguinto SG, Chambers G, Kasparian NA. Financial, opportunity and psychosocial costs of spinal muscular atrophy: an exploratory qualitative analysis of Australian carer perspectives. BMJ Open. 2018;8(5): e020907. https://doi. org/10.1136/bmjopen-2017-020907.

65. Park HB, Lee SM, Lee JS, Park MS, Park KI, Namgung R, et al. Survival analysis of spinal muscular atrophy type I. Korean J Pediatr. 2010;53(11):965-70. https://doi.org/10.3345/kjp.2010. 53.11 .965$.

66. Sakakihara Y, Yamanaka T, Kajii M, Kamoshita S. Long-term ventilator-assisted children in Japan: a national survey. Acta Paediatr Jpn. 1996;38(2):137-42. https://doi.org/10.1111/j.1442200x.1996.tb03456.x.

67. Sampson C, Garau M. How should we measure quality of life impact in rare disease? Recent learnings in spinal muscular atrophy. Office of Health Economics. Office of Health Economics. 2019. https://www.ohe.org/publications/how-should-we-measu re-quality-life-impact-rare-disease-recent-learnings-spinalmuscular. Accessed 13 Nov 2019.

68. Ali I, Gilchrist FJ, Carroll WD, Alexander J, Clayton S, Kulshrestha R, et al. Healthcare utilisation in children with SMA type 1 treated with nusinersen: a single centre retrospective 
review. BMJ Paediatr Open. 2019;3(1): e000572. https://doi.org/ 10.1136/bmjpo-2019-000572.

69. Aranda-Reneo I, Pena-Longobardo LM, Oliva-Moreno J, Litzkendorf S, Durand-Zaleski I, Tizzano EF, et al. The burden of spinal muscular atrophy on informal caregivers. Int J Environ Res Public Health. 2020;17(23):8989. https://doi.org/10.3390/ ijerph17238989.

70. Belter L, Cruz R, Kulas S, McGinnis E, Dabbous O, Jarecki J. Economic burden of spinal muscular atrophy: an analysis of claims data. J Mark Access Health Policy. 2020;8(1):1843277. https://doi.org/10.1080/20016689.2020.1843277.

71. Chambers GM, Settumba SN, Carey KA, Cairns A, Menezes MP, Ryan M, et al. Prenusinersen economic and health-related quality of life burden of spinal muscular atrophy. Neurology. 2020;95(1):e1-10. https://doi.org/10.1212/WNL.0000000000 009715.

72. Darba J, Marsa A. Patient characteristics and hospitalisation costs of spinal muscular atrophy in Spain: a retrospective multicentre database analysis. BMJ Open. 2019;9(11): e031271. https://doi. org/10.1136/bmjopen-2019-031271.

73. Darba J. Direct medical costs of spinal muscular atrophy in the Catalonia region: a population-based analysis. Clin Drug Investig. 2020;40(4):335-41. https://doi.org/10.1007/ s40261-020-00897-4.

74. Johnson NB, Proud C, Wassel CL, Dreyfus J, Cochrane T, Paradis AD. Characterization of adult patients with SMA treated in US hospital settings: a natural history study in the premier healthcare database. J Neuromuscul Dis. 2021;8(4):569-78. https://doi.org/10.3233/JND-200624.

75. McMillan HJ, Gerber B, Cowling T, Khuu W, Mayer M, Wu JW, et al. Burden of spinal muscular atrophy (SMA) on patients and caregivers in Canada. J Neuromuscul Dis. 2021;8(4):553-68. https://doi.org/10.3233/JND-200610.

76. Pena-Longobardo LM, Aranda-Reneo I, Oliva-Moreno J, Litzkendorf S, Durand-Zaleski I, Tizzano E, et al. The economic impact and health-related quality of life of spinal muscular atrophy: an analysis across Europe. Int J Environ Res Public Health. 2020;17(16):5640. https://doi.org/10.3390/ijerph17165640.

77. Tan H, Gu T, Chen E, Punekar R, Shieh PB. Healthcare utilization, costs of care, and mortality among patients with spinal muscular atrophy. J Health Econ Outcomes Res. 2019;6(3):185-95. https://doi.org/10.36469/63185.

78. Darba J. Management and current status of spinal muscular atrophy: a retrospective multicentre claims database analysis. Orphanet J Rare Dis. 2020;15(1):8. https://doi.org/10.1186/ s13023-019-1287-y.

79. Tetafort A, Couray-Targe S, Harmand S, Ansolabehere X, Maurel F, Hammes F. Assessing the real-world hospital economic burden of spinal muscular atrophy (SMA) In France. Value Health. 2017;20(9):A553. https://doi.org/10.1016/j.jval.2017.08.879.

80. Teynor M, Zhou J, Hou Q, Wells W, Hall E, Avendano J. Retrospective analysis of healthcare resource utilization (HRU) in patients with spinal muscular atrophy (SMA) in MarketScan ${ }^{\circledR}$ (P3.186). Neurology. 2017;88(16 Suppl.):P3.186.

81. Ali I, Gilchrist F, Carroll W, Alexander J, Clayton S, Willis T, et al. G176(P) Healthcare utilisation in SMA type 1 patients treated with nusinersen. Arch Dis Child. 2019;104(Suppl. 2):A71-2. https://doi.org/10.1136/archdischild-2019-rcpch.171.

82. Belter L, Jarecki J, Cruz R, O’Toole CM, O'Brien K, Reyna S, et al. Ambulation status, role participation and caregiver assistance among individuals with spinal muscular atrophy type III: results from the 2018 Cure SMA Membership Survey (P1.6061). Neurology. 2019;92(15 Suppl.):P1.6-061.

83. D'Angiolella LS, Belisari A, Mantovani LG, Sansone V, Vita G, Pane M. PND41: healthcare costs of patients with spinal muscular atrophy. Value Health. 2018;21:S336. https://doi.org/ 10.1016/j.jval.2018.09.2008.

84. Dabbous O, Seda J, Sproule DM. Economic burden of infantonset (Type 1) spinal muscular atrophy: a retrospective claims database analysis. Value Health. 2018;21:S251. https://doi.org/ 10.1016/j.jval.2018.04.1697.

85. Goble J, Dai D, Boulos F, Weng A, Johnson K, editors. The economic burden of spinal muscular atrophy patients in a commercially-insured population in the United States. In: AMCP Managed Care \& Specialty Pharmacy Annual Meeting. J Manag Care Spec Pharm. 2018;24(10-a):S49.

86. Goble J, Dai D, Song X, Shi N, Boulos F, Zhang L, et al. Travel burden of spinal muscular atrophy patients in the United States (P1.6-070). Neurology. 2019;92(15 Suppl):P1.6-070.

87. Mikecin L, Popović L, Meštrović J, Novak M, Galić S, Čulić $\mathrm{V}$, et al. Long term mechanicaly ventilated children: our experience. Paediatr Croat. 2009;53(1). https://hrcak.srce.hr/41164. Accessed 13 Nov 2019.

88. Moshe-Lilie O, Nizar C, Visser A, Dimitrova D, Karam C. Nusinersen in adults with spinal muscular atrophy, a single center experience (P4.4-015). Neurology. 2019;92(15 Suppl.):P4.-015.

89. Pelton T, Allen S, Helen C, Glover S. Case series report to observe feasibility of biweekly physiotherapy involving dynamic tilt table standing in ambulatory neuromuscular patients. Physiotherapy. 2016;102:e77-8. https://doi.org/10.1016/j.physio.2016. 10.074 .

90. Sansone VA, De Vivo DC, Bertini E, Hwu WL, Crawford TO, Swoboda KJ et al., editors. Nusinersen in infants who initiate treatment in a presymptomatic stage of spinal muscular atrophy (SMA): interim results from the phase 2 NURTURE study. In: 5th Congress of the European Academy of Neurology, Oslo. 2019;92(15):S25.001.

91. Shell R, Al-Zaidy S, Arnold W, Rodino-Klapac L, Prior T, Kotha $\mathrm{K}$, et al editors. AVXS-101 phase 1 gene therapy clinical trial in spinal muscular atrophy Type 1 (SMA1): improvement in respiratory and bulbar function reduces frequency and duration of hospitalizations compared to natural history. Hoboken: Wiley; 2018.

92. Wells W, Hall E, Scaife J, Hadker N, Miyasoto G. Determining the cost of care for spinal muscular atrophy using retrospective claims analysis. AMCP Managed Care \& Specialty Pharmacy Annual Meeting. J Manag Care Spec Pharm. 2017;23(3-a):S58.

93. Starner C, Gleason P, editors. Spinal muscular atrophy: an integrated medical and pharmacy claims analysis of nusinersen uptake and gene therapy forecast among 15 millon commercial insured [abstract]. J Manage Care Specialty Pharm. 2019;25(3-a):S54.

94. Malakhova AR, Krysanov IS, Vasilieva TP, Krasilnikova EY, Aleksandrova OY, Zinchenko RA, et al. The cost of specialized medical care of children under spinal muscular atrophy in Moscow. Probl Sotsialnoi Gig Zdravookhranenniiai Istor Med. 2021;29(1):80-5. https://doi.org/10.32687/ 0869-866X-2021-29-1-80-85.

95. Lopez Bastida J, Peña-Longobardo LM, Aranda-Reneo I, OlivaMoreno J, Litzkendorf S, Durand-Zaleski I, et al. PRO44. The economic impact and health-related quality of life of spinal muscular atrophy (SMA): an analysis across three European countries. Value Health. 2019;22:S848-9. https://doi.org/10.1016/j. jval.2019.09.2374.

96. Kockaya G, Oguzhan Ergın G, Çalışkan Z. PRO49. Annual cost of treatment of spinal muscular atrophy patients in Turkey. Value Health. 2019;22:S849-50. https://doi.org/10.1016/j.jval.2019.09. 2379.

97. Kolbin A, Vlodavets D, Kurylev A, Balykina YY, Proskurin M, Mishinova S, et al. The social-economic burden of spinal muscular atrophy in Russia. Farmakoekonomika. 2021;13(4):337-54. 
98. SMA UK. What two recent surveys told us about how SMA impacts patients' and caregivers' lives. 2019. https://smauk.org. uk/files/files/Research/Summary\%20of\%20Results\%202019.pdf. Accessed 13 Nov 2019.

99. Dangouloff T, Servais L. Clinical evidence supporting early treatment of patients with spinal muscular atrophy: current perspectives. Ther Clin Risk Manag. 2019;15:1153-61. https://doi.org/ 10.2147/TCRM.S172291.

100. Tizzano EF, Finkel RS. Spinal muscular atrophy: a changing phenotype beyond the clinical trials. Neuromuscul Disord. 2017;27(10):883-9. https://doi.org/10.1016/j.nmd.2017.05.011.

101. Wirth B. Spinal muscular atrophy: in the challenge lies a solution. Trends Neurosci. 2021. https://doi.org/10.1016/j.tins.2020. 11.009 .

102. Dangouloff T, Botty C, Beaudart C, Servais L, Hiligsmann M. Systematic literature review of the economic burden of spinal muscular atrophy and economic evaluations of treatments. Orphanet J Rare Dis. 2021;16(1):47. https://doi.org/10.1186/ s13023-021-01695-7.

103. Landfeldt E, Pechmann A, McMillan HJ, Lochmuller H, Sejersen T. Costs of illness of spinal muscular atrophy: a systematic review. Appl Health Econ Health Policy. 2021. https://doi.org/ 10.1007/s40258-020-00624-2.

104. Pannier AD. Spinal muscular atrophy: an update for managed care pharmacists. Am J Manag Care. 2021;27(1 Suppl.):S13-8. https://doi.org/10.37765/ajmc.2021.88593.

105. Al-Zaidy SA, Kolb SJ, Lowes L, Alfano LN, Shell R, Church KR, et al. AVXS-101 (onasemnogene abeparvovec) for SMA1: comparative study with a prospective natural history cohort. J Neuromuscul Dis. 2019;6(3):307-17. https://doi.org/10.3233/ JND-190403.

106. Baranello G, Darras BT, Day JW, Deconinck N, Klein A, Masson $\mathrm{R}$, et al. Risdiplam in Type 1 spinal muscular atrophy. N Engl J Med. 2021. https://doi.org/10.1056/NEJMoa2009965.

107. Darras BT, Chiriboga CA, Iannaccone ST, Swoboda KJ, Montes $\mathrm{J}$, Mignon L, et al. Nusinersen in later-onset spinal muscular atrophy: long-term results from the phase $1 / 2$ studies. Neurology. 2019;92(21):e2492-506. https://doi.org/10.1212/WNL.00000 00000007527.

108. De Vivo DC, Bertini E, Swoboda KJ, Hwu WL, Crawford TO, Finkel RS, et al. Nusinersen initiated in infants during the presymptomatic stage of spinal muscular atrophy: Interim efficacy and safety results from the phase 2 NURTURE study. Neuromuscul Disord. 2019;29(11):842-56. https://doi.org/10.1016/j.nmd. 2019.09.007.

109. Finkel RS, Chiriboga CA, Vajsar J, Day JW, Montes J, De Vivo DC, et al. Treatment of infantile-onset spinal muscular atrophy with nusinersen: a phase 2, open-label, dose-escalation study. Lancet. 2016;388(10063):3017-26. https://doi.org/10.1016/ S0140-6736(16)31408-8.

110. Lowes LP, Alfano LN, Arnold WD, Shell R, Prior TW, McColly $\mathrm{M}$, et al. Impact of age and motor function in a phase $1 / 2 \mathrm{~A}$ study of infants with SMA Type 1 receiving single-dose gene replacement therapy. Pediatr Neurol. 2019;98:39-45. https://doi.org/10. 1016/j.pediatrneurol.2019.05.005.

111. Montes J, Dunaway Young S, Mazzone ES, Pasternak A, Glanzman AM, Finkel RS, et al. Nusinersen improves walking distance and reduces fatigue in later-onset spinal muscular atrophy. Muscle Nerve. 2019;60(4):409-14. https://doi.org/10.1002/mus. 26633.

112. Waldrop MA, Kolb SJ. Current treatment options in neurologySMA therapeutics. Curr Treat Options Neurol. 2019;21(6):25. https://doi.org/10.1007/s11940-019-0568-z.

113. Kay DM, Stevens CF, Parker A, Saavedra-Matiz CA, Sack V, Chung WK, et al. Implementation of population-based newborn screening reveals low incidence of spinal muscular atrophy. Genet Med. 2020;22(8):1296-302. https://doi.org/10.1038/ s41436-020-0824-3.

114. Ross LF, Kwon JM. Spinal muscular atrophy: past, present, and future. NeoReviews. 2019;20(8):e437-51. https://doi.org/10. 1542/neo.20-8-e437.

115. Cusco I, Bernal S, Blasco-Perez L, Calucho M, Alias L, FuentesPrior $\mathrm{P}$, et al. Practical guidelines to manage discordant situations of SMN2 copy number in patients with spinal muscular atrophy. Neurol Genet. 2020;6(6): e530. https://doi.org/10.1212/NXG. 0000000000000530

116. Wadman RI, Stam M, Gijzen M, Lemmink HH, Snoeck IN, Wijngaarde CA, et al. Association of motor milestones, SMN2 copy and outcome in spinal muscular atrophy types $0-4$. J Neurol Neurosurg Psychiatry. 2017;88(4):365-7. https://doi.org/10. 1136/jnnp-2016-314292.

117. Prior TW, Bayrak-Toydemir P, Lynnes TC, Mao R, Metcalf JD, Muralidharan K, et al. Characterization of reference materials for spinal muscular atrophy genetic testing: a Genetic Testing Reference Materials Coordination Program Collaborative Project. J Mol Diagn. 2021;23(1):103-10. https://doi.org/10.1016/j.jmoldx. 2020.10.011.

118. Farrar MA, Kiernan MC. Spinal muscular atrophy: the dawning of a new era. Nat Rev Neurol. 2020;16(11):593-4. https://doi. org/10.1038/s41582-020-00410-7. 